\title{
Distribution and habitat use of the western sand darter (Ammocrypta clara) and the eastern sand darter (Ammocrypta pellucida) in the Elk River, West Virginia
}

\author{
Patricia A. Thompson
}

Follow this and additional works at: https://researchrepository.wvu.edu/etd

\section{Recommended Citation}

Thompson, Patricia A., "Distribution and habitat use of the western sand darter (Ammocrypta clara) and the eastern sand darter (Ammocrypta pellucida) in the Elk River, West Virginia" (2016). Graduate Theses, Dissertations, and Problem Reports. 6800.

https://researchrepository.wvu.edu/etd/6800

This Thesis is protected by copyright and/or related rights. It has been brought to you by the The Research Repository @ WVU with permission from the rights-holder(s). You are free to use this Thesis in any way that is permitted by the copyright and related rights legislation that applies to your use. For other uses you must obtain permission from the rights-holder(s) directly, unless additional rights are indicated by a Creative Commons license in the record and/ or on the work itself. This Thesis has been accepted for inclusion in WVU Graduate Theses, Dissertations, and Problem Reports collection by an authorized administrator of The Research Repository @ WVU. For more information, please contact researchrepository@mail.wvu.edu. 
Distribution and habitat use of the western sand darter (Ammocrypta clara) and the eastern sand darter (Ammocrypta pellucida) in the Elk River, West Virginia

\title{
Patricia A. Thompson
}

\author{
Thesis submitted to the \\ Davis College of Agriculture, Natural Resources and Design \\ at West Virginia University \\ in partial fulfillment of the requirements for the degree of \\ Master of Science \\ in \\ Wildlife and Fisheries Resources
}

\author{
Stuart A. Welsh, Ph.D., Chair \\ Dan Cincotta, MS \\ Michael Strager, Ph.D.
}

Division of Forestry and Natural Resources

\author{
Morgantown, West Virginia
}

2016

Keywords: Ammocrypta, benthic habitat, distribution, habitat use, sand, substrate Copyright 2016 Patricia Thompson 


\section{Abstract \\ Distribution and habitat use of the western sand darter (Ammocrypta clara) and the eastern sand darter (Ammocrypta pellucida) in the Elk River, West Virginia}

\section{Patricia A. Thompson}

This thesis examines the distribution and habitat use of two sympatric sand darter species, the western sand darter (Ammocrypta clara) and the eastern sand darter (A. pellucida). This thesis includes three chapters: (1) an introduction and literature review on the western and eastern sand darters, habitat use, and species distribution models; (2) a substrate selection laboratory experiment; and, (3) an evaluation of sympatric sand darter habitat use at multiple scales in the Elk River. Sand darters are slender, sand-dwelling fishes that were once broadly distributed, but have since undergone range-wide population declines, presumably owing to habitat loss. Habitat use studies have been conducted for the eastern sand darter, but literature on the western sand darter remains sparse, and is an essential element for the conservation of the species. The laboratory study (chapter 2) evaluated substrate selection for each species by conducting 15 trials in four aquaria; two aquaria contained six western sand darters in each, while the other two held a combination of both species, three eastern sand darters and three western sand darters. The sand darters were given the choice to bury into five equally available and randomly positioned substrates: fine sand $(0.12-0.25 \mathrm{~mm})$, medium sand $(0.25-0.5 \mathrm{~mm})$, coarse sand $(0.5-1.0 \mathrm{~mm})$, very coarse sand $(1.0-2.0 \mathrm{~mm})$, and granule gravel $(2.0-4.0 \mathrm{~mm})$. The western sand darter selected for coarse and medium sand, while the eastern sand darter was more of a generalist selecting for fine, medium, and coarse sand. Substrate selection was significantly different $(p=0.02)$ between species in the same environment, where the western sand darter selected for coarser substrate more often compared to the eastern sand darter. The habitat use assessment (chapter 3) addressed the distribution, sandbar habitat use, and landscape scale analysis of sand darter habitat in the lower 190 river $\mathrm{km}$ of the Elk River. A total of 63 sites were sampled. Western sand darters were detected at eight sites, eastern sand darters were detected at 47 sites, and neither species was detected at 14 sites. The two species were sympatric at six sites. At the sandbar scale, western sand darters were detected in sandbars with greater area, higher proportions of coarse grain sand and faster average current velocity, while the eastern sand darter was more of a generalist using a wider range of sandbar habitats. The landscape-level analysis revealed that drainage area was an important predictor for both species, while sinuosity also contributed to the western sand darter's habitat suitability. Sandbar quality (area, grain size, and velocity) and fluvial geomorphic variables (drainage area and sinuosity) are likely key driving factors structuring sand darter distributions in the Elk River. This multiscale study of species substrate selection, distribution and habitat use is unique, given that only a few sympatric populations are known of western and eastern sand darters. 


\section{Acknowledgements}

I would like to thank Dr. Stuart Welsh, the West Virginia Division of Natural Resources, the West Virginia Cooperative Fish and Wildlife Research Unit, and the WVU Division of Forestry and Natural Resources for the opportunity to conduct research on two unique sanddwelling fish species. I would like to dedicate a special thank you to my advisor Dr. Stuart Welsh, for his mentorship, statistical assistance, and fish identification advice. Thanks also to Dr. Mike Strager and Dan Cincotta for serving on my graduate committee.

A special thanks to my field and laboratory help for spending an extensive amount of time dragging a small meshed seine through the sand: Austin Rizzo, Joni Aldinger, Kevin Lambert, Brian Crabill, and Bri Tierney. A special thanks to Austin Rizzo, Joni Aldinger, Dustin Smith, and Corbin Shilling for being great friends and supportive labmates. Thanks also to Becky Nestor for always being there and Dr. Pat Mazik for her mentorship and career advice. I would also like to thank the West Virginia Libraries Inter Library Loan program for always locating obscure fish reports in a timely manner.

Lastly, I would like to thank my friends and family for their unwavering support and encouragement throughout the past two years. My family always encouraged me to follow my dreams and make my passion my career. Finally, a special thanks to Ben Johnson for his support throughout this process and his willingness to read a draft or help me with sampling in the laboratory and in the field. 


\section{Table of Contents}

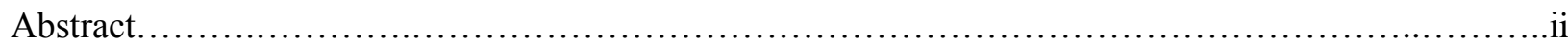

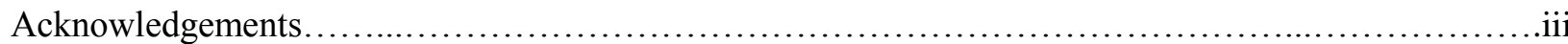

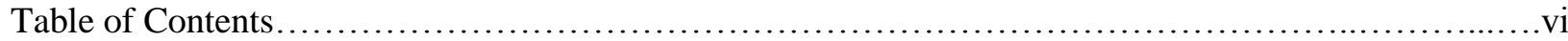

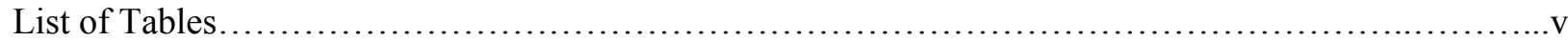

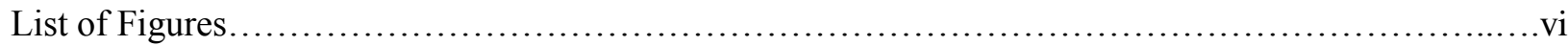

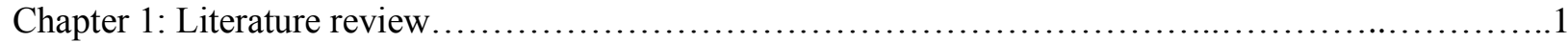

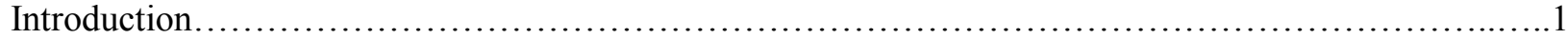

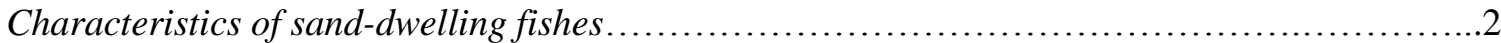

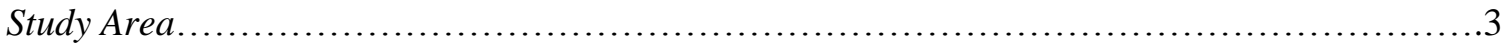

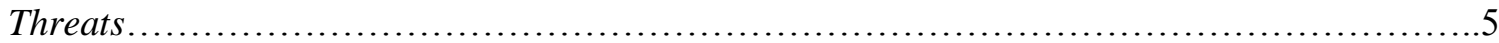

Species distribution models and habitat use ...............................................

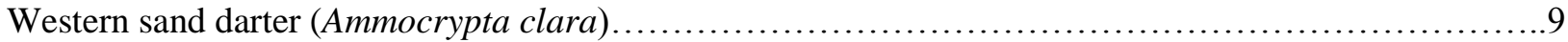

Physical description, reproduction, and feeding ..........................................

Habitat use .........................................................................

Distribution and conservation status.................................................... 12

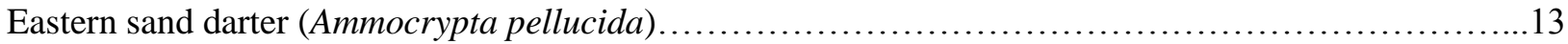

Physical description, reproduction, and feeding ..........................................

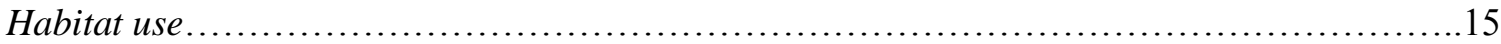

Community associations..............................................................

Distribution and conservation status......................................................

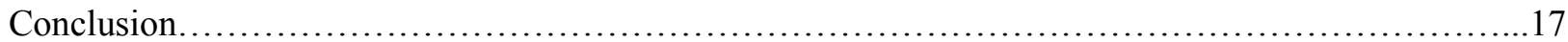

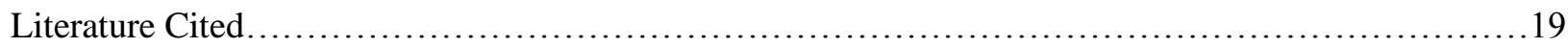

Chapter 2: Effect of substrate size on sympatric sand darter benthic habitat preferences..................36

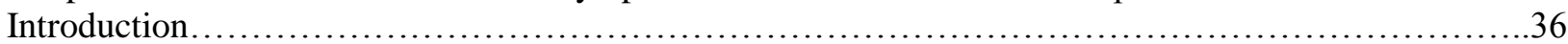

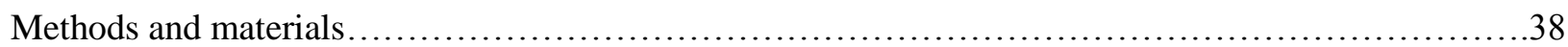

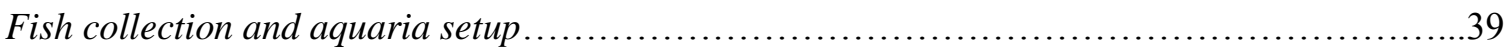

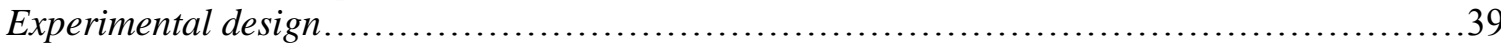

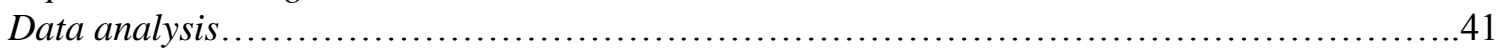

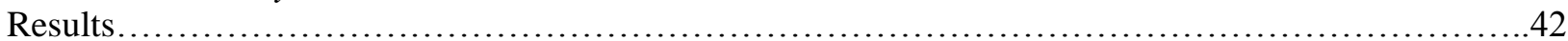

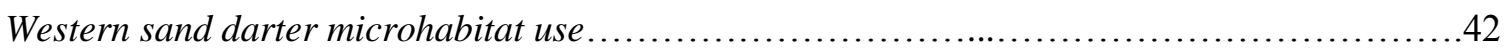

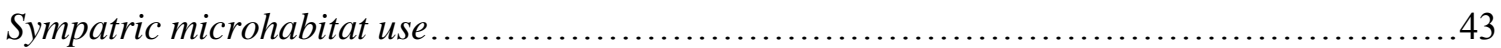

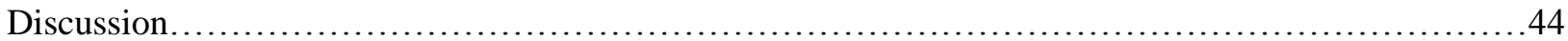

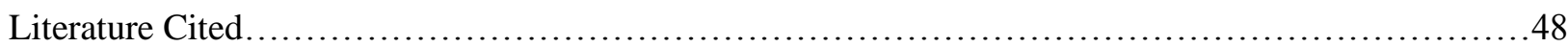

Chapter 3: A multiscale investigation of habitat use and within-river distribution of sympatric sand darter

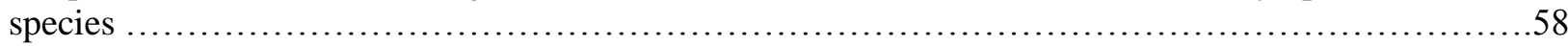

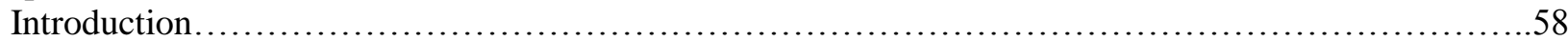

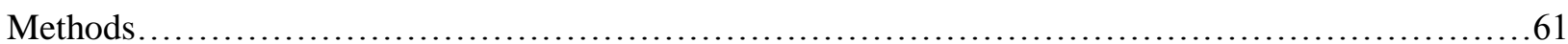

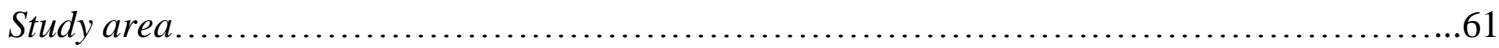

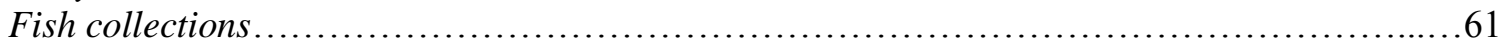

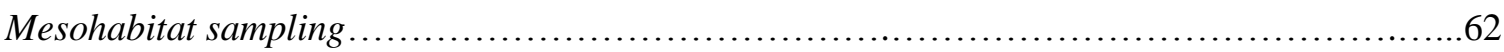

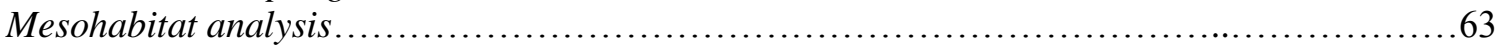

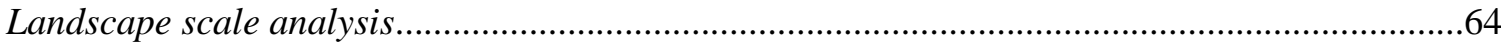

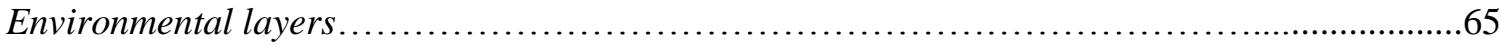

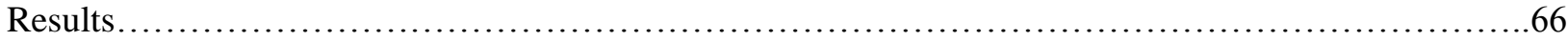

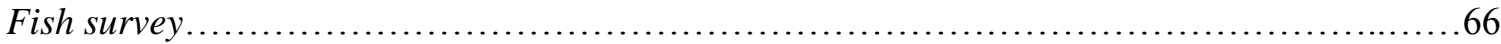

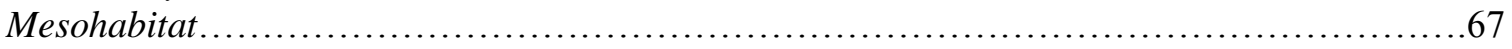

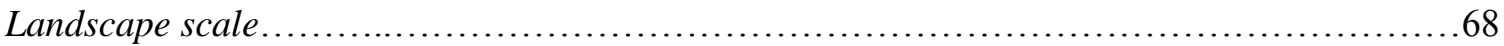

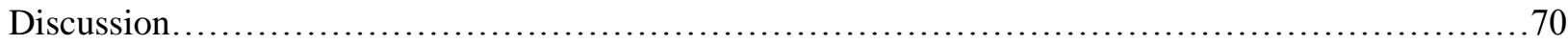

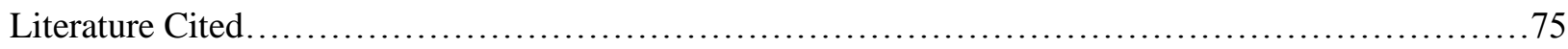




\section{List of Tables}

Table 1.1 A literature review of the substrate size used by western (A. clara) and eastern (A.

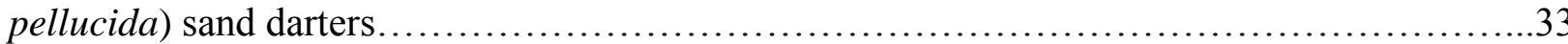

Table 2.1. Substrate selection ratio estimates and the Bonferroni confidence intervals for the western sand darter only aquaria and combined species aquaria. Selection ratio values $>1$ indicate selection, while values $<1$ indicate avoidance. An asterisk $*$ indicates significant selection

Table 2.2. Pairwise comparison with Bonferroni confidence intervals for the western sand darter only and combined species aquaria. An asterisk * indicates significant selection. The substrate categories used for the study included fine sand (FS), medium sand (MS), coarse sand (CS), and very coarse sand (VCS).

Table 3.1. Means, standard errors (SE) and ranges of western and eastern sand darter habitat use variables for 63 sites in the Elk River, WV. Western sand darters were detected at 8 sites, eastern sand darters were detected at 47 sites, and neither species were detected at 14 sites. A total of 6 sites contained both species. Bottom current velocity (FCV) and average current velocity (ACV) for the site and sandbar.

Table 3.2. Mean values for percent composition of sandbar grain size, standard error (SE) and ranges. Sand samples for the western sand darter were collected at 6 sites, and 36 sites for the eastern sand darter

Table 3.3. The principal components $(\mathrm{PC})$ with eigenvalues $>1.0$, the percent variance explained by each PC, and a list of variables examined by principal components analysis (PCA) with their corresponding factor loading. Bolded factor loading ( $>0.40)$ were used to interpret the

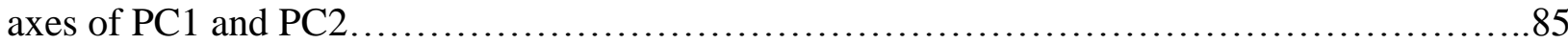

Table 3.4. Environmental layers used to generate the species distribution models 86

Table 3.5. The estimates of the relative percent contribution of the environmental variables to the maxent models created for the western and eastern sand darters 


\section{List of Figures}

Figure 1.1 A) Eastern sand darter, B) western sand darter, C) partially buried eastern sand darter with cryptic sand-like pigmentation, D) example of sand darter resting behavior. .34

Figure 1.2. Map of the Elk River watershed shaded by elevation with the counties highlighted by

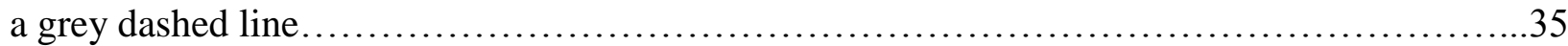

Figure 2.1. Map of the lower $190 \mathrm{rkm}$ of the Elk River watershed shaded by elevation below the dam (black rectangle) in Sutton, WV. Western sand darters have been detected from Mink Shoals to Clendenin and eastern sand darters have been detected from Mink Shoals to Frametown. The black circles represent the three sand darter collection locations. ...

Figure 2.2. Western sand darter only experiment (A), western sand darters from the combined aquarium (B), eastern sand darters from the combined aquaria (C), and combined selection results (D). Values above the dashed line at one indicate selection and values below indicate avoidance. Bonferroni $95 \%$ confidence intervals that do not contain the value of one are

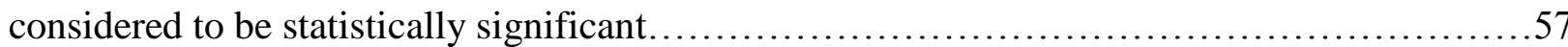

Figure 3.1. Western and eastern sand darter sampling locations in the lower $190 \mathrm{rkm}$ of the Elk

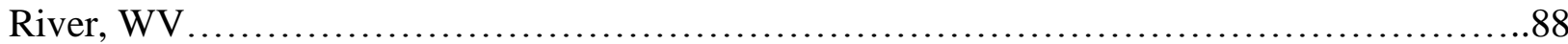

Figure 3.2. Principal components analysis plot of sand darter habitat use with overlaid polygons showing the variance between species. Each point represents a sampling site where either western sand darters (W) or eastern sand darters (E) were detected. Axis loadings $>0.40$ are

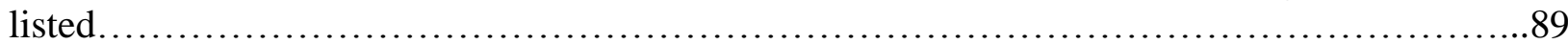

Figure 3.3. Probability of suitable habitat for the western sand darter (WSD) and eastern sand darter (ESD) by 14 digit HUC catchments in the lower Elk River............................90

Figure 3.4. The response curves demonstrate how contributing drainage area and sinuosity affect the maxent predictions for the western sand darter (WSD) and the eastern sand darter (ESD). The curves show how the logistic prediction changes as the environmental variables are varied, keeping all other environmental variables at their average value. Contributing drainage area is in thousands (i.e., $1.0=1,000$ ). 


\section{Chapter 1: Literature review}

\section{Introduction}

A rich fauna of freshwater fishes in the southeastern United States represents nearly $50 \%$ of North America's freshwater fish diversity, including approximately 350 species in Appalachia (Mayden et al. 1992; Warren et al. 1997; Lévêque et al. 2008). The number of jeopardized native fishes in the southeastern United States has increased by $75 \%$ since 1989 , with $28 \%$ of extant species listed as endangered, threatened or vulnerable (Warren et al. 2000). The imperiled state of many of these species is attributed to fish habitat degradation that reduces and often fragments populations (Etnier 1997; Warren et al. 2000). Conservation of many of these rare freshwater species hinges on improved water quality and the protection of habitat, which is largely dependent on pinpointing species distributions, understanding habitat use, and identifying areas with quality habitat (Grandmaison et al. 2004).

Tucked away in central West Virginia, the Elk River is regarded as a system with exceptional biological diversity. The river supports close to 90 species of native fishes, including 19 species of darters, three of which are rare sand-dwelling species: western sand darter Ammocrypta clara (Jordan \& Meek, 1885), eastern sand darter Ammocrypta pellucida (Putnam, 1863), and diamond darter Crystallaria cincotta (Welsh \& Wood, 2008) (Cincotta \& Welsh 2010; Welsh et al. 2013). These unique sand-dwelling darters have experienced a similar pattern of range decline within the southeastern United States, presumably owing to habitat reduction, modification, and/or destruction (Jelks et al. 2008). As a result, the western and eastern sand darters are classified as vulnerable in the American Fisheries Society imperiled fishes report (Jelks et al. 2008), and have a threatened or critical status throughout the majority of their range 
(e.g., Warren et al. 2000; Grandmaison et al. 2004). Likewise, the diamond darter is federally endangered, with only one known extant population located in the Elk River (USFWS 2013). Though these three species have experienced localized extirpations, all have managed to persist in the lower Elk River. Additionally, the western and eastern sand darters are the only sympatric sister species of Ammocrypta (Near 2000), and the Elk River is one of the few remaining places

where both species occur (Cincotta \& Welsh 2010). This presents a unique opportunity to study the western and eastern sand darter where they are sympatric, to gain further insight on the distribution range and habitat use of sand darters in the Elk River.

Although both species are of conservation concern, literature pertaining to the western sand darter is sparse, and there is a lack of information from areas where both species are sympatric (Table 1.1). In West Virginia, the two are sympatric in the Elk River within the lower 36 river $\mathrm{km}(\mathrm{rkm})$, while the eastern sand darter is reported as being commonly found up to 135 rkm from the mouth (Cincotta \& Welsh 2010; personal observation). The restricted range of the western sand darter compared to the eastern sand darter in the Elk River is of conservation concern, since this is the only known location in West Virginia where the western sand darter persists, and represents the eastern extent for both species (Cincotta \& Welsh 2010).

\section{Characteristics of sand-dwelling fishes}

Sand-dwelling fishes are some of the least studied species of all freshwater and marine fishes, although the sandy environments these fishes inhabit are structurally simple, wide-spread, and common throughout the world (Zuanon et al. 2006). Many sand-dwelling species of freshwater fish reside in large rivers that have a broad distribution of sandy beds and low complexity of specialized habitat (Hobson \& Chess 1986; Zuanon et al. 2006). The number of 
studies concerning sand-dwelling fishes is limited, in part owing to the rareness of many species and difficulties associated with sampling and observing them in sandy habitats (Carvalho et al. 2014). Organisms that occupy and thrive in sandy environments are regarded as psammophiles, and possess a combination of specialized traits to flourish in a habitat of predominantly sand (e.g., Schaefer et al. 2005; Zuanon et al. 2006; Carvalho et al. 2014). Common characteristics of psammophilous fishes include occupying benthic habitats, nocturnal or crepuscular behavior, cryptic pigmentation, small body size, translucent bodies, large eyes, and burying or probing behavior (Hobson \& Chess 1986; Zuanon et al. 2006). Species within Ammocrypta are considered to be psammophiles, and much like the Amazonian sand-dwelling fishes described by Zuanon et al. (2006), fishes in the genus Ammocrypta generally inhabit moderate to large rivers, are elongate, slightly translucent, and are known for burying in the sand (Williams 1975). To bury, sand darters will rapidly plunge head first into the sand, and swiftly flick their body slightly upward to fully bury just below the surface of the substrate (Williams 1975; Daniels 1989). While buried, individuals will often nudge the snout just above the surface of the sand, barely exposing the eyes (Fig. 1.1).

\section{Study area}

The Elk River is a part of the Appalachian Plateau Physiographic Province, an area that gently slopes towards the northwest to merge with the Interior Plains. This region is characterized by lush steep valleys with narrow flood plains carved out by rivers with underlying porous soils that facilitate absorption from rainfall (Strager 2008; USFWS 2013). The Elk River is a tributary of the Kanawha River, a part of the Ohio River drainage, and the greater

Mississippi River watershed. Throughout its course, the Elk River has an elevation change of 
approximately $900 \mathrm{~m}$ and roughly drains $4,000 \mathrm{~km}^{2}$ of the Appalachian Plateau (Stauffer et al. 1995). Similar to many other watersheds in Appalachia, the Elk River is impacted by timbering, oil and gas drilling, coal mining, chemical production, urban development and agriculture (Strager 2008).

The Elk River follows an east to west course, meandering $290 \mathrm{rkm}$ through rugged forests, farms and cities. The river begins in Slatyfork and terminates at the capital city of Charleston, where the Elk confluences with the Kanawha River. The headwaters of the Elk River are just a trickle as they flow through rugged karst topography, consisting of a subterranean network of caves, streams, and waterfalls. The river then goes underground for a portion of its course in Randolph County and remerges near Elk Springs. Downstream from Elk Springs the river is crystal clear and gains momentum until it encounters Sutton Lake, a $6 \mathrm{~km}^{2}$ impounded reservoir. Further downstream away from the tailwaters of the dam the river loses momentum, grows warmer, and becomes emerald green in color. The study area of my thesis research is the lower $190 \mathrm{rkm}$ of the Elk River below the dam in Sutton, WV (Fig. 1.2).

The lower $50 \mathrm{rkm}$ of the Elk River serves as habitat for the sole known remaining population of diamond darters, and the lower $36 \mathrm{rkm}$ supports the only known population of western sand darters within the state of WV (Cincotta \& Welsh 2010). The lower $50 \mathrm{rkm}$ is federally protected and designated as critical habitat for the diamond darter (USDOI 2013), as well the lower Elk River is listed as an area of primary conservation concern by the state (WVDNR 2015). Past studies have focused largely on the lower $36 \mathrm{rkm}$ of the Elk River where the diamond darter, western sand darter, and eastern sand darter are located. This stretch of the river is characterized by low gradient and sinuosity with long deep pools separated by short shoals (Welsh et al. 2013). 


\section{Threats}

Western and eastern sand darters face similar threats, as documented in published literature (Williams 1975; Kuehne \& Barbour 1983; Page 1983), and species status reports (Holm \& Mandrake 1996; Grandmaison et al. 2004; Adams \& Burr 2004; COSSARO 2009). The primary threats for sand darters consist of siltation, erosion of stream banks, impoundment and channelization of rivers, stream flow modification, water pollution (from oil fields and agricultural runoff), coal mining, highway construction, and residential development. A status assessment of the eastern sand darter by Grandmaison et al. (2004) also acknowledged the potential for overutilization from scientific collections, disease, predation, invasive species, inadequate existing regulatory mechanisms, and decreased genetic variation.

Population declines are primarily attributed to siltation of preferred substrate, which decreases a fish's ability to bury and conserve energy, reduces oxygen uptake (e.g., gill clogging), and impacts egg survivorship (Holm \& Mandrak 1996; Facey 1998). A study that examined environmental impacts on the growth of eastern sand darters, reported that $82 \%$ of growth was attained during the first year, and individuals with the greatest first year growth occurred in sand-dominated and high mean annual discharge environments (Drake et al. 2008). Drake et al. (2008) speculated that the strong positive relationship of age- 0 growth and high mean annual discharge are related to the flood-pulse concept, where high discharge events decrease the amount of siltation, and increase nutrient inputs to nearshore areas (Junk et al. 1989). In other rivers discharge has been shown to influence cohort success via the maintenance of sandy depositional habitats and the increased nutrient inputs from the flood-pulse events (Gutreuter et al. 1999; Lin \& Caramaschi 2005). Dams, which are present in many low gradient 
rivers that sand darters inhabit, alter seasonal flow and temperature regimes, change sediment scour and deposition, and alter the transport of particulate organic matter (e.g., Baxter 1977). Silt-free sand bars are a requirement for both species; however, many sand bars located in large river systems have been degraded as a result of channel dredging, dike, levee, and reservoir construction (Zeman \& Brooks 2004).

\section{Species distribution models and habitat use}

The conservation of rare freshwater stream fish is often limited by the deficiency of spatial distribution data and information regarding the association between environmental variables and distribution patterns (Olden et al. 2002; Gibbson et al. 2004). In general, a species distribution is tightly linked with a number of environmental variables, which influence areas that are suitable for survival (Guisan \& Zimmermann 2000). Thus environmental variables associated with species presence can be used to generate a species potential distribution (Anderson \& Martinez-Meyer 2004). The western and eastern sand darters are vulnerable to anthropogenic threats in the watershed (Jelks et al. 2008), but information is sparse regarding whether or not environmental factors play a role in limiting the distribution of western sand darters in the Elk River. By modeling a species distribution, it is possible to elucidate patterns that define a species range within a given landscape (Warren et al. 2000). Predictive species distribution models (SDMs) are becoming a crucial aspect of biodiversity conservation (Guisan \& Zimmermann 2000), as the conservation of rare stream fishes is largely dependent upon understanding habitat use in order to identify areas for protection, inventory, and restoration (Angermeier et al. 2002; Royle et al. 2007). 
The majority of SDMs utilize presence and absence data (e.g., generalized linear models, generalized additive models, boosted regression trees, and random forest), which are collected from systematic sampling events (Elith et al. 2006). However, species that are rare or threatened typically have restricted distributions, are habitat specialists, and have a limited number of known occurrence locations (Hernandez et al. 2006). This is the case for the western and eastern sand darters in the Elk River. Because the sand darters are elusive they could be present at a site, but not detected. Consequently, only presence locations can be modeled. Maximum entropy modeling (maxent) is one of the few methods designed specifically for presence-only data (Phillips et al. 2006). This method is being regularly employed to examine the probability of occurrence of rare stream fishes that are of conservation concern or have limited geographic information (Endries 2011; Williams et al. 2012; Liang et al. 2013; Albanese et al. 2014).

Additionally, maxent is effective with small sample sizes as low as 5, 10, and 25 (Hernandez et al. 2006; Elith et al. 2011). Maximum entropy refers to the entropy of a probability distribution that is equal to or greater than all other specified classes of the probability distributions (Phillips et al. 2004). The output of maxent is a map of the probability of occurrence of a species, which is also used to as a proxy for the relative suitability of habitat in a given region or a species given niche (Phillips et al. 2006; Warren \& Seifert 2011). Elith et al. (2011) described some of the applications of maxent modeling, which include predicting current distributions, examining variables that correlate with species occurrence, predicting potential areas of range expansion, predicting species richness or diversity, as well as a tool to examine how distributions change through time (e.g., land use alteration and climate change).

The process of choosing ecologically relevant environmental factors that reflect the targets species interplay between geographic and environmental processes at an appropriate scale 
is an important step when creating an SDM (Guisan \& Zimmerman 2000; Phillips et al. 2006). In order to accomplish this task, preliminary field observations are needed to better understand a target species habitat requirements, population status, and movement extent (Gusian \& Thuiller 2005). Modeling can never fully replace the need for field observations, but rather can be used as a tool to guide the management and conservation efforts for threatened stream fishes, especially when occurrence data are incomplete, budgets are limited, or when a study area is inaccessible (Gusian \&Thuiller 2005). Other considerations, are the challenges associated with modeling a species in a riverine system, as a result of the need to incorporate the spatial arrangement of fish habitat, which varies through time and space (Nilsson et al. 2003; Liang et al. 2013). Adding to the complexity, research in riverine systems is exceedingly multidisciplinary with the need to have an understanding of hydrology, geomorphology, ecology, and economics (Nilsson et al. 2003).

Fish habitat within a river is influenced by water quality, energy source, substrate, channel morphology, flow regimes, and thermal regimes, which are all determined by the various watershed scale factors like surficial geology, soil type, bedrock type and depth, watershed topography, land cover, and climate (Wiley et al. 1997; Wang et al. 2003). Furthermore, the structure and size of a stream influences habitat availability and largely determines the aquatic biological community (e.g., Vannote et al. 1980). Aquatic ecosystems can be subdivided into various classes depending on scale: ecosystems (watershed), streams and rivers, macrohabitats (headwaters, midsized stream, and large rivers), mesohabitats (riffle, run, pool, backwater), and microhabitats (depth, velocity, substrate type, cover) (Fisher et al. 2012). Beyond the large watershed scale variables (e.g., geology and climate), which are the architects behind instream 
fish habitat (Knighton 1998), it is also important to understand the microhabitat use of coexisting species.

Areas of quality habitat are a fundamental component of a fish's ability to grow, survive, and reproduce (Fisher et al. 2012). Darters are benthic fish that reside in rivers and lakes (Kuehne \& Barbour 1983). Many species coexists, but are segregated by differences in microhabitat use (e.g., Fisher \& Pearson 1987). Substrate composition, depth, and flow velocity are recognized as the primary factors influencing the microhabitat use of darters (e.g., Chipps \& Perry 1994; Welsh \& Perry 1998; Welsh et al. 2013). Burying in sand substrate is an integral component of the life history of western and eastern sand darters; therefore, determining grain size preference is an essential aspect for the conservation and management of both species (Kuehne \& Barbour 1983; Drake et al. 2008). Information gained from habitat use studies may be used to help manage and restore local instream and riparian habitat (White 1996). Below I provide further literature review on the western sand darter and the eastern sand darter focused on the following topics: physical description, reproduction, feeding, habitat use, distribution, and conservation status.

\section{Western sand darters (Ammocrypta clara)}

Physical description, reproduction, and feeding

The western sand darter is a small, benthic, sand-dwelling fish that superficially resembles and is often mistaken for its sister species the eastern sand darter. A circumstance that transpired in the Elk River of West Virginia, where for many years the western sand darter went undetected or was misidentified as the eastern sand darter (Cincotta \& Welsh 2010). The western sand darter can be distinguished from the eastern sand darter by the presence of a needle-like 
prolonged opercular spine, pigmentation dissimilarities, anal fin origin, and scale row counts (Linder 1959; Baily et al. 2004). The species Latin name 'clara' refers to the clear or transparent flesh that becomes light yellow dorsally (Williams 1975; Fig. 1.1). A thin line of pigment stretches the full length of the body just below the lateral line, and sometimes merges with the 9 to 13 dusky lateral blotches that become more prominent posteriorly (Linder 1959; Williams 1975; Page 1983). The pigmentation present on the western sand darter is a cryptic sand-like pattern of small dark blotches against a translucent to light yellow body (Fig. 1.1). The anal fin origin on the western sand darter is slightly in advance of the second dorsal fin (Baily et al. 2004). Western sand darters generally have fewer scales compared to the eastern sand darter, with 5 to 6 transverse scales, and 2 scales below the lateral line (Page 1983). Cincotta \& Welsh (2010) found the population from the Elk River has a mean of 5.1 transverse scales, and a mean of 2.5 scales below the lateral line. Driver \& Adams (2013) examined 379 western sand darters from Arkansas, noting a mean size of $42.9 \mathrm{~mm}$ standard length (SL), with males and females reaching sexual maturity between 35 to $40 \mathrm{~mm} \mathrm{SL}$.

Male western sand darters are distinguished from females by pigment, presence of breeding tubercles, as well as dorsal and anal fin lengths (Williams 1975; Simon 2006). Generally, the thin line of pigment laterally and the lateral blotches are more prominent on males (Williams 1975). Breeding tubercles begin to develop in early May to June, are fully developed between June and July, and are present on the males pelvic, anal, and caudal fins (Williams 1975). The dorsal fin and anal fin are sexually dimorphic, Driver \& Adams (2013) described the male anal fin as approximately $3 \mathrm{~mm}$ longer than that of the female, while the male dorsal fins are $2 \mathrm{~mm}$ longer. 
The spawning behavior of the western sand darter was observed in the field by Simon et al. (1992) in Wisconsin at a water temperature of $22^{\circ} \mathrm{C}$, where the females swam into a group of males, partially buried into coarse sand, and then proceeded to quiver in the sand where the eggs were presumed to be laid. Similarly, Driver \& Adams (2013) observed spawning behavior in laboratory aquaria and reported that western sand darters spawned in pairs or groups during dawn or dusk by vibrating and burying the caudal peduncle in the sand. Eggs from that study were found singly in the sand and were slightly adhesive with a mean diameter of $1.22 \mathrm{~mm}$. Driver \& Adams (2013) also reported female standard length has a positive effect on clutch size.

Compared to other Ammocrypta, western sand darters hatch at the smallest size $(4.1 \mathrm{~mm}$ TL), and larvae are entirely unpigmented at the time of hatching (Simon et al. 2002). Upon hatching the larvae have well developed jaws, and a long oval yolksac that is absorbed at $7.0 \mathrm{~mm}$ TL (Simon et al. 1992). Driver \& Adams (2013) observed adults in aquaria exhibiting crepuscular behavior, meaning they were predominately active during a simulated period of dawn or dusk and otherwise completely or partially buried in the sand. Western sand darters feed on drifting prey (Driver \& Adams 2013), and likely have a similar diet compared to the eastern sand darter given the similarities in habitat use. Eastern sand darters feed predominantly on Chironomus, and other aquatic invertebrates to a lesser extent (Spreitzer 1979).

\section{Habitat use}

Western sand darters are an extremely habitat selective species, occurring in low to moderate gradient rivers with large extensive sand deposits, and are rarely detected in small streams with only small, intermittently distributed sand areas (Kuehne \& Barbour 1983). The species is found in moderate to swift currents over sand or fine gravel substrate (Pflieger 1971; 
Etnier \& Starnes 1993; Page \& Burr 2011). Alternatively, a record from Pflieger (1971) noted western sand darters in Missouri at times avoided strong currents and were found in shallow backwater areas, as well as quiet margins of a drainage canal at depths up to $1.5 \mathrm{~m}$. Simon et al. (1992) observed the species spawning in the wild and described the habitat as an area on the downstream side of an island with a slow current over coarse sand.

\section{Distribution and conservation status}

The western sand darters distribution is concentrated along the Mississippi River system and Lake Michigan drainage, with fragmented populations in the Ohio River drainage (Williams 1975; Cincotta \& Welsh 2010; Page \& Burr 2011). The distribution of the species extends as far north as Minnesota, southward to Texas, and eastward to West Virginia (Page \& Burr 2011). The Southeastern Fishes Council Technical Advisory Committee listed the species as vulnerable, because only minor habitat disturbances could render the species at risk for becoming threatened or endangered (Warren et al. 2000). The alterations of many river systems has likely led to the western sand darter's sporadic distribution. The species is considered to be extremely rare in the southeastern United States (Page \& Burr 2011).

The western sand darter has been given a conservation status in 13 of the 15 states within its range. In Illinois, the western sand darter is listed as state endangered, owing to a lack of suitable habitat (Zeman \& Brooks 2004). State threatened listings include Iowa, Louisiana, Tennessee, and Virginia, while the species is similarly of concern in Arkansas, Indiana, Kentucky, Missouri, Texas, and Wisconsin. The species is of greatest conservation need in Oklahoma, and rare in Michigan. Western sand darters are extirpated from Mississippi, as a result of reductions in the amount of suitable habitat from siltation (Pezold et al. 1993). In 
Minnesota, western sand darter populations are considered stable (Driver \& Adams 2013). In West Virginia, the species is listed as critically imperiled and is of primary conservation concern, because of the limited population and high risk of extinction (WVDNR 2015).

Within the Ohio River drainage, the western sand darter was extirpated from portions of the Wabash River drainage, but still occurs in the White River in Indiana (Simon 2006). The western sand darter was almost considered to be extirpated from the state of Kentucky, because the species went undetected for over 50 years. In 1996, two fish biologists sampled a sandy shoal in the upper Green River and discovered two specimens, which were initially mistaken as the eastern sand darter (Cicerello \& Laudermilk 1996). Later, the western sand darter was also discovered in the North Fork of the Kentucky River (Cicerello \& Laudermilk 1996). The western sand darter was similarly rediscovered in the upper Tennessee River drainage (TN, VA) (Starnes et al. 1977; Etnier \& Starnes 1993), and the Cumberland River (KY, TN) (Jenkins \& Burkhead 1994). The recent discovery of the western sand darter in the early 2000's in the Elk River of West Virginia extended the range distribution of the species to the Eastern Highlands region of North America, and added an additional expanse where the western sand darters range overlaps with the eastern sand darter (Cincotta \&Welsh 2010).

\section{Eastern sand darters (Ammocrypta pellucida)}

Physical description, reproduction, and feeding

The specific epithet of the scientific name for the eastern sand darter was derived from the Latin word 'pellucidus' meaning translucent or transparent, which describes the overall body of this delicate fish (Williams 1975; Fig. 1.1). At first glance, the eastern sand darter resembles

its sister species the western sand darter. Linder et al. (1959) revisited differences between the 
two, noting the opercle on the eastern sand darter is triangular with a small pointed corner that lacks a well-defined spine. Likewise, the eastern sand darter has a higher number of scale rows, and a greater amount of pigmentation on the body compared to the western sand darter (Linder 1959). In addition, Bailey et al. (2004) noted that the anal fin insertion of the eastern sand darter is below or slightly posterior to the insertion of the second dorsal fin, whereas the anal fin insertion of the western sand darter is slightly forward. Williams (1975) describes the eastern sand darter as being the most elongate of the genus Ammocrypta, with 12-16 small dark olive spots along the dorsal ridge that become paired posterior to the dorsal fin, and a series of 9-14 dusky-olive spots along the lateral line. The top of the head and the upper lip likewise have dusky blotches (Kuehne \& Barbour 1983). The small dark blotches dorsally and laterally on a slightly translucent to yellow body resembles sand (Williams 1975). Along with pigmentation and opercle differences, Page (1983) included two scales counts as diagnostic characters, 11-13 transverse scales, and 5-6 scales below the lateral line of the eastern sand darter.

Sexual dimorphism is present, though the dissimilarities are subtle (Spreitzer 1979; Johnston 1989). Breeding males develop tubercles between the $1^{\text {st }}$ and $3^{\text {rd }}$ fin rays on the ventral side of the pelvic fins, along with dark pigmentation on the pelvic fin membranes (Williams 1975; Spreitzer 1979; Johnston 1989). The male anal fin is longer compared to the females (Spreitzer 1979). Likewise, the males genital papillae is smaller and never extends to contact the base of the anal fin spine, while the females genital papillae is more elongated, and may touch the base of the anal fin spine (Spreitzer 1979).

Johnston (1989) observed the spawning behavior, noting the species primarily spawned in pairs, or less frequently with two males (addition of a "sneaker male") and one female. Eastern sand darter eggs are slightly adhesive, translucent, and spherical (Johnston 1989). Mating pairs 
buried eggs singularly into the substrate by vibrating the caudal fins into the sand (Johnston 1989). No nesting behavior or parental care was noted (Johnston 1989). To date, the species has not been observed spawning in the field. During the Johnston (1989) study, spawning occurred between April and June at waters temperatures of 20.5 to $23^{\circ} \mathrm{C}$, with a mean egg diameter of 1.4 $\mathrm{mm}$. Eastern sand darter larvae hatch at $5.5 \mathrm{~mm}$ TL, and yolk sac absorption is complete around $7.4 \mathrm{~mm}$ TL (Simon et al. 1992). Compared to the other five Ammocrypta species, the eastern sand darter has the most heavily pigmented larvae (Simon et al. 1992). Adults reach sexual maturity at $36 \mathrm{~mm}$ SL (Spreitzer 1979), and grow to lengths of around $84 \mathrm{~mm}$ TL (Page \& Burr 2011). Spreitzer (1979) reported age at first maturity at one year, along with a correlation between fecundity and total length.

The maximum observed life span for the eastern sand darter was previously thought to be two years (Coker et al. 2001), until Drake et al. (2008) examined eastern sand darters ages from Ontario streams using scales and otoliths, and discovered fish up to four years in age. Eastern sand darter diets consist of predominately Chironomidae (Forbes \& Richardson 1921; Tuner 1922), while other less frequently consumed taxa include oligochaetes, annelids, cladocerans, dipteran larvae, ephemeropteran nymphs, trichopteran larvae, plecopteran nymphs, copepods, ostracods, terrestrial mites and terrestrial insects (Spreitzer 1979). During a laboratory study, Spreitzer (1979) observed the species feeding during the day and suggested sand darters are sight feeders. Slow motion video of the feeding behavior revealed that eastern sand darters strike prey from 5 to $10 \mathrm{~mm}$ away and draw the prey into the mouth by expanding the orobranchial chamber to create negative pressure (Spreitzer 1979).

\section{Habitat use}


Eastern sand darters spend the majority of the time buried in sandy beds of medium to large rivers or lakes, in areas with a low current, and an abundance of sandy substrate (e.g., Williams 1975; Facey 1998; Daniels 1993; Dextrase et al. 2014). The eastern sand darter is one of the utmost habitat selective species of freshwater fishes, being that the species associates with areas of greater than 90\% fine to medium sand and are silt-intolerant (e.g., Daniels 1993; Table 1.1). The burying behavior was investigated by Daniels (1989) using laboratory trials to test three previously described hypotheses: predator avoidance, prey capture, and energy conservation. Predator avoidance and prey capture did not elicit a burying response, but eastern sand darters did bury in response to discharge fluctuations. These findings led to the conclusion that the species buries in the sand to conserve energy, while maintaining their position in the river (Daniels 1989).

Habitat use by the eastern sand darter was examined by Daniels (1993) through field and laboratory experiments, and in both scenarios the darters exclusively associated with sand substrates, while water velocity, depth, and distance from the bank had little to no effect on an individual's distribution. Facey \& O'Brien (2004) examined the eastern sand darters sand grain size preferences and reported the species used sand particles between 0.12 and $0.54 \mathrm{~mm}$, while only a few individuals were found in areas where the particle size exceeded $1.0 \mathrm{~mm}$. Dextrase et al. (2014) studied occupancy of the eastern sand darter in two Ontario rivers noting the detectability of the species was highly related to substrate (i.e., lower detection probability with increasing substrate size), while occupancy was positively related to proportions of sand and fine gravel, as well as water clarity. Thus, areas of clean sand are an essential facet of the eastern sand darter's life history (Holm \& Mandrak 1996; Drake et al. 2008). 


\section{Community associations}

A number of studies reported other fishes commonly associated or captured with eastern sand darters, which generally consisted of Cyprinidae, Percidae, and some Ictaluridae (Daniel 1993, Donovan 2009; Tesslar 2012). Daniels (1993) described a correlation between the abundance of eastern sand darters and bluntnose minnows (Pimephales notatus), fallfish (Semotilus corporalis), and tessellated darters (Etheostoma olmstedi) in Vermont. Although, the positive correlation was only significant for the abundance of eastern sand darters and tessellated darters. The most abundant species commonly collected with eastern sand darters in Illinois included steelcolor shiners (Cyprinella whipplei), spotfin shiners (C. spiloptera), bluntnose minnows, bullhead minnows (P. vigilax), sand shiners (Notropis stramineus), silverjaw minnows (N. buccatus), and dusky darters (Percina sciera) (Donovan et al. 2009). In the Maumee River of Ohio, Tesslar et al. (2012) documented fishes caught with eastern sand darters, which consisted of spotfin shiners, redfin shiners (Lythrurus umbratilis), ghost shiners (N. buchanani), sand shiners, bluntnose minnows, channel catfish (Ictalurus punctatus), and brindled madtoms (Noturus miurus). Additionally, the eastern sand darter is speculated as being a potential glochidial host for an endangered mussel in Ontario (Fisheries and Oceans Canada 2013). A host relationship between the round hickorynut mussel (Obovaria subrotunda) and the eastern sand darter was suggested by Clarke (1977). This relationship has not been tested, however both species are found in the East Sydenham River, where one of the few populations of round hickorynut mussels persists (COSWIC 2009).

\section{Distribution and conservation status}


Eastern sand darters are distributed throughout the lower Great Lakes (Lakes Huron, Erie, and Ontario), the St. Lawrence River and Lake Champlain drainages, with fragmented populations in Illinois, Indiana, Kentucky and West Virginia (Williams 1975; Page \& Burr 2011). The northern Lake Champlain and St. Lawrence River populations are genetically distinct compared to the more southern populations in the lower Great Lakes and Ohio River drainage (Ginson et al. 2015). Previous to the West Lake (Lake Ontario basin) discovery, there was a 500 km separation between the northern and southern populations (Reid \& Dextrase 2014). Although, the northern and southern populations are genetically distinct, the genetic affinity of the West Lake population is unknown (Reid \& Dextrase 2014).

The species is listed as state threatened in Illinois, Michigan, New York, Ohio, and Vermont. In Pennsylvania, the eastern sand darter is listed as state endangered. The endangered designation is a result of the species restricted range in two creeks and Lake Erie, as well as possible extirpations from the Monongahela and Youghiogheny rivers (Cooper 1983; Grandmaison et al. 2004). The species is listed as vulnerable in West Virginia (WVDNR 2015). In Indiana and Kentucky, there is no listing for the species. Recently in Indiana, the eastern sand darter was delisted as a species of special concern following a statewide survey that revealed a wider distribution than previous thought, including rediscoveries in rivers where the species had not been recorded in over a century (INDNR 2004). Eastern sand darters are protected under the endangered species act in Canada, where the species is listed as threatened in Quebec and endangered in Ontario (COSSARO 2009; Fisheries and Oceans Canada 2012). The listing in Ontario was recently changed to endangered in 2010, because of range-wide declines, extirpation from Ontario streams, and vulnerability to habitat alterations and invasive species (Fisheries and Oceans Canada 2012). However, eastern sand darters will recolonize areas where improved land 
use practices have reduced the amount of sediment entering the stream (Tesslar 2012; Hopkins and Zimmerman 2014).

\section{Conclusion}

Ammocrypta are commonly considered rare and elusive, which has resulted in a scarcity of information regarding distribution and habitat preferences (Kuehne \& Barbour 1983). In many places Ammocrypta are the sole sand-dwelling species of freshwater fish, which adds to the biodiversity of aquatic ecosystems. Furthermore, the type of rivers that the western and eastern sand darters occupy (i.e., moderately large rivers with a low gradient) coincide with many characteristics common to areas of urban development, industrialization, and agriculture. The species face many threats from adverse anthropogenic practices in the watershed, however with improved land use practices, and proper environmental regulatory mechanisms, it is possible to

protect and enhance sand darter populations (COSWIC 2009; Tessaler 2012). A range extension for the western sand darter was documented in the Elk River of West Virginia, and added a new location in the upper Ohio River drainage (Cincotta \& Welsh 2010). Further research is needed in the Elk River to identify factors influencing population trends or limiting the distribution of the species. Information gained by studying these species may provide insight on the health and overall quality of an aquatic ecosystem, especially in these large river systems that are under stress from dense human population, urban development, and agriculture.

This literature review supports my thesis research on the distribution and habitat use of the western sand darter and the eastern sand darter in the Elk River. My research chapters focus on 1) a laboratory based experiment examining substrate selection preferences, and 2) sand darter sandbar habitat use and landscape-level factors influencing the probability of suitable 
habitat in the Elk River. My research on the distribution and habitat use of western and eastern sand darters presents an opportunity to add to the growing literature concerning these highly specialized sand-dwelling fish assemblages. Further, my research results will inform conservation and management decisions by the West Virginia Division of Natural Resources.

\section{Literature cited}

Adams, G. L., and B. M. Burr. 2004. Conservation assessment for the Eastern Sand Darter, Ammocrypta pellucida. Report submitted to the Hoosier National Forest, USDA Forest Service, Bedford, IN.

Albanese, B., T. Litts, M. Camp, and D. A. Weiler. 2014. Using occupancy and species distribution models to assess the conservation status and habitat use of the goldline darter (Percina aurolineata) in Georgia, USA. Ecology of Freshwater Fish 23(3):347-359.

Anderson, R. P., and E. Martinez-Meyer. 2004. Modeling species' geographic distributions for preliminary conservation assessments: an implementation with the spiny pocket mice (Heteromys) of Ecuador. Biological Conservation 116:167-179.

Angermeier P. L., K. L. Krueger, and C. A. Dolloff. 2002. Discontinuity in stream fish distributions: implications for assessing and predicting species occurrence. Pages 519527 in J. M. Scott, P. J. Heglund, M. L. Morrison, J. B. Haufler, M. G. Raphael, W. A. Wall and F. B. Samson, editors. Predicting Species Occurrences: Issues of Accuracy and Scale. Island Press, Covelo, California.

Bailey, R. M., W. C. Latta, and G. R. Smith. 2004. An atlas of Michigan fishes with keys and illustrations for their identification. Misc. Pub. Museum of Zoology, University of Michigan, No. 192. p. 52. 
Baxter, R. M. 1977. Environmental effects of dams and impoundments. Annual Review of Ecology and Systematics 8:255-283.

Carvalho, M. S., J. Zuanon, and E. J. Ferreira. 2014. Diving in the sand: the natural history of Pygidianops amphioxus (Siluriformes: Trichomycteridae), a miniature catfish of Central Amazonian streams in Brazil. Environmental biology of fishes 97(1):59-68.

Chipps, S.R., W. B. Perry, and S. A. Perry. 1994. Patterns of microhabitat use among four species of darters in three Appalachian streams. American Midland Naturalist 131:175180.

Cicerello, R. R., and E. L. Laudermilk. 1996. Rediscovery of the western sand darter (Ammocrypta clara). Kentucky State Nature Preserves Commission. Naturally Kentucky, No. 18, pp. 6.

Cincotta, D. A., and S. A. Welsh. 2010. Discovery of Ammocrypta clara (Western Sand Darter) in the Upper Ohio River of West Virginia. The American Midland Naturalist 163(2): 318-325.

Clarke, A. H. 1977. The endangered mollusks of Canada. In: T. Mosquin and C. Suchal (eds.) Canada'a threatened species and habitats. Canadian Nature Federation Special Publication Number 6. p. 148-150.

Coker, G. A., C. B. Portt, and C. K. Minns. 2001. Morphological and ecological characteristics of Canadian freshwater fishes. Fisheries and Oceans Canada, Ottawa. Man. Rep. Fish. Aquat. Sci. 2554.

Cooper, E. L. 1983. Fishes of Pennsylvania and the Northeastern United States. The Pennsylvania State University Press, University Park and London, Pennsylvania. 243 p. 
COSSARO 2009, Candidate Species as Risk Evaluation Form for Eastern Sand Darter (Ammocrypta pellucida). Committee on the Status of Species at Risk in Ontario, Nov. 2009.

COSEWIC 2009. Committee on the Status of Endangered Wildlife in Canada assessment and status report on the Eastern Sand Darter Ammocrypta pellucida, Ontario populations and Quebec populations. Ottawa, Canada.

Daniels, R. A. 1989. Significance of burying in Ammocrypta pellucida. Copeia 1989: 29-34.

Daniels, R. A. 1993. Habitat of the Eastern Sand Darter, Ammocrypta pellucida. Journal of Freshwater Ecology 8:287-295.

Dextrase, A. J., Mandrak, N. E., and Schaefer, J. A. 2014. Modelling occupancy of an imperiled stream fish at multiple scales while accounting for imperfect detection: implications for conservation. Freshwater Biology 59(9):1799-1815.

Donovan, B. H., L. J. Pitcher, and C. E. Beachum. 2009. Status survey and management implications of the Harlequin Darter and Eastern Sand Darter in Southeastern Illinois. State Wildlife Grant Final Report, Illinois Department of Natural Resources, Project No. T-37-P-1.

Drake, D. A. R., M. Power, M. A. Koops, S. E. Doka, and N. E. Mandrak, 2008. Environmental factors affecting growth of eastern sand darter (Ammocrypta pellucida). Canadian Journal of Zoology 86:714-722.

Driver, L. J. and G. L. Adams. 2013. Life history and spawning behavior of the Western Sand Darter (Ammocrypta clara) in Northeast Arkansas. The American Midland Naturalist 170(2):199-212. 
Elith, J., C. H. Graham, R. P. Anderson, M. Dudı'k, S. Ferrier, A. Guisan, R. J. Hijmans, F. Huettmann, J. R. Leathwick, A. Lehmann, J. Li, L. G. Lohmann, B. A. Loiselle, G. Manion, C. Moritz, M. Nakamura, Y. Nakazawa, J. McC. Overton, A. Townsend Peterson, S. J. Phillips, K. Richardson, R. Scachetti-Pereira, R. E. Schapire, J. Soberón, S. Williams, M. S. Wisz, and N. E. Zimmermann. 2006. Novel methods improve prediction of species' distributions from occurrence data. Ecography 29(2):129-151.

Elith, J., S. J. Phillips, T. Hastie, M. Y. Dudík, E. Chee, and C. J. Yates. 2011. A statistical explanation of MaxEnt for ecologists. Diversity and distributions 17(1): 43-57.

Endries, M. 2011. Aquatic Species Mapping in North Carolina Using Maxent. U. S. Fish and Wildlife Service, Ecological Services Field Office, Ashville, NC.

Etnier, D. A. and W. C. Starnes. 1993. The Fishes of Tennessee. University of Tennessee Press, Knoxville, TN.

Etnier, D. A. 1997. Jeopardized southeastern freshwater fishes: a search for causes. Pages 88-104 in G. W. Benz and D. E. Collins, eds. Aquatic fauna in peril: the Southeastern perspective. Special Publ. 1, Southeast Aquatic Research Inst., Lenz Design and Communications, Decatur, GA.

Facey, D. E. 1998. The status of the eastern sand darter, Ammocrypta pellucida, in Vermont. Canadian Field-Naturalist. 112(4):596-601.

Facey, D. E. and S. M. O’Brien. 2004. Influence of substrate composition on distribution of eastern sand darters (Ammocrypta pellucida) in the Poultney River. Pages 291 - 297 in T. O. Manley, P. L. Manley, and T. B. Mihuc, editors. Lake Champlain: partnerships and research in the new millennium. Kluwer Academic/Plenum Publishers, New York, NY. 
Fisheries and Oceans Canada. 2012. Recovery strategy for the Eastern Sand Darter (Ammocrypta pellucida) in Canada: Ontario populations. Species at Risk Act Recovery Strategy Series, Fisheries and Oceans Canada, Ottawa.

Fisheries and Oceans Canada. 2013. Recovery Strategy for the Round Hickorynut (Obovaria subrotunda) and the Kidneyshell (Ptychobranchus fasciolaris) in Canada. Species at Risk Act Recovery Strategy Series. Fisheries and Oceans Canada. Ottawa.

Fisher, W. L., and W. D. Pearson. 1987. Patterns of resource utilization among four species of darters in three central Kentucky streams. Community and evolutionary ecology of North American stream fishes. University of Oklahoma Press, Norman, 69-76.

Fisher, W. L., A. B. Bozek, J. C. Vokoun, and R. B. Jacobson. 2012. Freshwater aquatic habitat measurements. Pages 101-150 in A. V. Zale, D. L. Parish, and T. M. Sutton, editors. Fisheries techniques, $3^{\text {rd }}$ edition. American Fisheries Society, Bethesda, MD.

Forbes, S.A. and R.E. Richardson. 1920. The Fishes of Illinois. Illinois Natural History Survey, 2nd ed., 493 pp.

Gibson, L. A., B. A., Wilson, D. M. Cahill, and J. Hill. 2004. Spatial prediction of rufous bristlebird habitat in a coastal heathland: a GIS-based approach. Journal of applied Ecology 41(2):213-223.

Ginson, R., R. P. Walter, N. E. Mandrak, C. L. Beneteau, and D. D. Heath. 2015. Hierarchical analysis of genetic structure in the habitat-specialist Eastern Sand Darter (Ammocrypta pellucida). Ecology and evolution 5(3):695-708.

Grandmaison, D., J. Mayasich, and D. Etnier. 2004. Eastern sand darter status assessment. US Fish and Wildlife Service, Region, 3. NRRI Technical Report No. NRRI/TR-2003/40. 
Guisan, A., and N. E. Zimmermann. 2000. Predictive habitat distribution models in ecology. Ecological modelling 135(2):147-186.

Gutreuter, S., A. D. Bartels, K. Irons, and M. B. Sandheinrich. 1999. Evaluation of the floodpulse concept based on statistical models of growth of selected fishes of the Upper Mississippi River system. Canadian Journal of the Fisheries and Aquatics Science. $56: 2282-2291$.

Hernandez, P. A., C. H. Graham, L. L. Master, and D. L. Albert. 2006. The effect of sample size and species characteristics on performance of different species distribution modeling methods. Ecography 29(5):773-785.

Hobson, E. S., and J. R. Chess. 1986. Relationships among fishes and their prey in a nearshore sand community off southern California. Environmental Biology of Fishes 17(3):201226.

Holm, E. and N. E. Mandrak. 1996. The status of the Eastern sand darter, Ammocrypta pellucidia, in Canada. Canadian Field-Naturalist 110(3):462-469.

Hopkins, R. L., and B. Zimmerman. 2014. First Observation of the Eastern Sand Darter (Ammocrypta pellucida) in Raccoon Creek (Ohio River Basin) in Southeastern Ohio in 57 Years. Northeastern Naturalist, 21(1), N13-N17.

INDNR 2004. Eastern sand darter is removed from state special concern list. Wildlife Diversity Section Annual Report, Division of Fish and Wildlife Indiana Department of Natural Resources, pp.23.

Jelks, H. L., S. J. Walsh, N. M. Burkhead, S. Contreras-Balderas, E. Diaz-Pardo, D. A. Hendrickson, J. Lyons, N. E. Mandrak, F. McCormick, J. S. Nelson, S. P. Platania, B.A. Porter, C. B. Renaud, J. J. Schmitter-Soto, E. B. Taylor, and M. L. Warren Jr. 2008. 
Conservation Status of Imperiled North American Freshwater and Diadromous Fishes. Fisheries 33(8):372-407.

Jenkins, R.E. and N. M. Burkhead. 1994. Freshwater fishes of Virginia. American Fisheries Society, Bethesda, Maryland.

Johnston, C. E. 1989. Spawning in the eastern sand darter, Ammocrypta pellucida (Pisces: Percidae) with comments on the phylogeny of Ammocrypta and related taxa. Transactions of the Illinois Academy of Sciences 82(3-4):163-168.

Junk, W. J., P. B. Bayley, and R. E. Sparks. 1989. The flood pulse concept in river-floodplain systems. Canadian Special Publication of Fisheries and Aquatic Sciences 106(1):110127.

Knighton, A. D. 1998. Fluvial forms and processes: a new perspective. Oxford University Press, NY.

Kuehne, R. A. and R. W. Barbour. 1983. The American Darters. The University Press of Kansas. $177 \mathrm{pp}$.

Lévêque, C., T. Oberdorff, D. Paugy, M. L. J. Stiassny, and P. A. Tedesco. 2008. Global diversity of fish (Pisces) in freshwater. Pages 545-567 in Freshwater Animal Diversity Assessment. Springer, Netherlands.

Liang, L., S. Fei, J. B. Ripy, B. L. Blandford, and T. Grossardt. 2013. Stream habitat modelling for conserving a threatened headwater fish in the Upper Cumberland River, Kentucky. River Research and Applications 29(10):1207-1214. 
Lin, D. S. C. and T. P. Caramaschi. 2005. Responses of the fish community to the flood pulse and siltation in a floodplain lake of the Trombetas River, Brazil. Hydrobiologia 545:7591.

Linder, A. D. 1959. The American Percid Fishes Ammocrypta clara Jordan and Meek and Ammocrypta pellucida (Baird). The Southwestern Naturalist 4(4):176-184.

Mayden, R. L., B. M. Burr, L. M. Page, and R. R. Miller. 1992. The native freshwater fishes of North America. Pages 825-863 in R. L. Mayden, editor. Systematics, historical ecology, and North American freshwater fishes. Stanford University Press, Stanford, California.

Near, T. J., J. C. Porterfield, and L. M. Page. 2000. Evolution of cytochrome b and the molecular systematics of Ammocrypta (Percidae: Etheostomatinae). Copeia 2000(3): 701-711.

Neebling, T. E., and M. C. Quist. 2008. Observations on the Distribution and Status of Western Sand Darter, Spotted Gar, and Skipjack Herring in Iowa Rivers. Journal of the Iowa Academy of Science 115(1-4): 24-27.

Nilsson, C., J. E. Pizzuto, G. E. Moglen, M. A. Palmer, E. H. Stanley, N. E. Bockstael, L. C. Thompson. 2003. Ecological forecasting and the urbanization of stream ecosystems: challenges for economists, hydrologists, geomorphologists, and ecologists. Ecosystems $6(7): 659-674$.

O'Brien, S. M., and D. E. Facey. 2008. Habitat use by the Eastern Sand Darter, Ammocrypta pellucida, in two Lake Champlain tributaries. The Canadian Field-Naturalist 122(3):239246.

Olden, J. D., Jackson, D. A., and Peres-Neto, P. R. 2002. Predictive models of fish species distributions: a note on proper validation and chance predictions. Transactions of the American Fisheries Society 131(2):329-336. 
Page, L. M. 1983. Handbook of darters. TFH Publications, Neptune City, NJ.

Page, L. M. and B. M. Burr. 2011. Peterson field guide to freshwater fishes of North America and North of Mexico. Second edition, Houghton Mifflin Harcourt, Boston, MA. pp. 534535.

Pezold, F., N. H. Douglas, and S. G. George. 1993. A Status Survey of the Western Sand Darter, Ammocrypta clara, in the Big Black River, Mississippi. Southeastern Fishes Council Proceedings 1(27):2-6.

Pflieger, W. L. 1971. A distributional study of Missouri fishes. Museum of Natural History, University of Kansas Publication 20:225-570.

Phillips, S. J., M. Dudík, and R. E. Schapire. 2004. A maximum entropy approach to species distribution modeling. In Proceedings of the twenty-first international conference on Machine learning, p. 83.

Phillips, S. J., R. P. Anderson, and R. E. Schapire. 2006. Maximum entropy modeling of species geographic distributions. Ecological modelling 190(3):231-259.

Reid, S., and A. Dextrase. 2014. First record of Ammocrypta pellucida (Agassiz, 1863)(Actinopterygii: Perciformes) from the Lake Ontario drainage basin. Check List 10(5):1201-1203.

Royle J. A., M. Kery, R. Goutier, and H. Schmid. 2007. Hierarchical spatial models of abundance and occurrence from imperfect survey data. Ecological Monographs 77, 465481.

Schaefer, S. A., F. Provenzano, M. de Pinna, and J. N. Baskin. 2005. New and noteworthy Venezuelan Glanapterygine catfishes (Siluriformes, Trichomycteridae), with discussion of their biogeography and psammophily. American Museum Novitates 3496:1-27. 
Simon, T. P. 2006. Biodiversity of fishes in the Wabash River: status, indicators, and threats. In Proceedings of the Indiana Academy of Science 115(2):136-148.

Simon, T. P., E. J. Tyberghein, K. J. Scheidegger, and C. E. Johnston. 1992. Descriptions of protolarvae of the sand darters (Percidae: Ammocrypta and Crystallaria) with comments on systematic relationships. Ichthyological Exploration of Freshwaters 3:347-358.

Simon, T. P. 1993. Assessment of the range of the threatened darter, Ammocrypta pellucida (Putnam), from the Maumee Basin, Indiana. In Proceedings of the Indiana Academy of Science 102(1-2):139-146.

Spreitzer, A.E. 1979. The life history, external morphology and osteology of the eastern sand darter, Ammocrypta pellucida (Putnam, 1863), an endangered Ohio species (Pisces: Percidae). M.S. Thesis. The Ohio State University, 248 p.

Starnes, W. C., D. A. Etnier, L. B. Starnes, and N. H. Douglas. 1977. Zoogeographic implications of the rediscovery of the percid genus Ammocrypta in the Tennessee River drainage. Copeia 1977(4):783-786.

Stauffer Jr, J., J. M. Boltz, and L. R. White. 1995. Fishes of West Virginia. Academy of Natural Sciences 146:1-389.

Strager, J. M. 2008. Diamond darter (Crystallaria cincotta) status review, treat assessment data development. Final Report, U.S. Fish and Wildlife Service, Elkins, WV.

Strayer, D. L., and D. Dudgeon. 2010. Freshwater biodiversity conservation: recent progress and future challenges. Journal of the North American Benthological Society 29(1):344-358. 
Tessler, N. R., J. F. Gottgens, and M. R. Kibbey. 2012. The first observations of the Eastern Sand Darter, Ammocrypta pellucida (Agassiz), in the Ohio portion of the Maumee River mainstem in sixty-five years. The American Midland Naturalist 167(1):198-204.

Tucker, J. K., and F. A. Cronin. 1996. The Western Sand Darter (Ammocrypta clara) in Pool 26 of the Mississippi River in Missouri and Illinois. Transactions of the Illinois State Academy of Science 89(3 and 4) 221-224.

Turner, C.L. 1921. Food of the common Ohio darters. The Ohio Journal of Science 22:41-62.

USDOI (United States Department of Interior) 2013. Federal Register, Endangered and Threatened Wildlife and Plants; Designation of Critical Habitat for the Diamond Darter (Crystallaria cincotta) Vol. 78, No. 163.

USFWS (United States Fish and Wildlife Service) 2013. Endangered and threatened wildlife and plants; endangered species status for diamond darter. Federal Register 78: 45074-45095.

Vannote, R. L., G. W. Minshall, K. W. Cummins, J. R. Sedell, and C. E. Cushing. 1980. The river continuum concept. Canadian Journal of Fisheries and Aquatic Sciences 37(1):130137.

Wang, L., J. Lyons, P. Rasmussen, P., Seelbach, T. Simon, M. Wiley, P. Kanehl, E. Baker, S. Niemela, and P. M. Stewart. 2003. Watershed, reach, and riparian influences on stream fish assemblages in the Northern Lakes and Forest Ecoregion, USA. Canadian Journal of Fisheries and Aquatic Sciences 60(5):491-505.

Warren Jr, M. L., P. L Angermeier, B. M. Burr, and W. R. Haag. 1997. Decline of a diverse fish fauna: patterns of imperilment and protection in the southeastern United States. Aquatic fanua in peril: the southeastern perspective. Decatur, GA: Lenz Design and Communications: 105-164. 
Warren Jr, M. L., B. M. Burr, S. J. Walsh, H. L. Jr. Bart, R. C. Cashner, D. A. Etnier, and S. T. Ross. 2000. Diversity, distribution, and conservation status of the native freshwater fishes of the southern United States. Fisheries 25(10):7-31.

Warren, D. L., and S. N. Seifert. 2011. Ecological niche modeling in Maxent: the importance of model complexity and the performance of model selection criteria. Ecological Applications 21(2):335-342.

Welsh, S. A., and S. A. Perry. 1998. Habitat partitioning in a community of darters in the Elk River, West Virginia. Environmental Biology of Fishes 51:411-419.

Welsh, S. A., D. M. Smith, and N. D. Taylor. 2013. Microhabitat use of the diamond darter. Ecology of Freshwater Fish 22:587-595.

White, R. J. 1996. Growth and development of North American stream habitat management for fish. Canadian Journal of Fisheries and Aquatic Science 53(1):342-363.

Wiley, M. J., S. L. Kohler, and P. W. Seelbach. 1997. Reconciling landscape and local views of aquatic communities: lessons from Michigan trout streams. Freshwater Biology 37:133148.

Williams, J. D. 1975. Systematics of the percid fishes of the subgenus Ammocrypta, genus Ammocrypta, with descriptions of two new species. Bulletin of the Alabama Museum of Natural History 1:1-56.

Williams, L., C. Smith, and C. Wolf. 2012. Using ecological niche modeling to predict the probability of occurrence of rare fish and mussel species in East Texas. Endangered Species Program, Texas Parks and Wildlife Service, Austin, TX.

WVDNR, 2015. West Virginia State Wildlife Action Plan, West Virginia Division of Natural Resources, Draft June 10, 2015, Elkin, WV. 
Zeman, D. K., and B. M. Brooks. 2004. Status survey of the Sturgeon Chub, Macrhybopis gelida, the Bigeye Shiner, Notropis boops, and Western Sand Darter, Ammocrypta clara, and the Crayfish, Orconectes placidus, in the Middle Mississippi River, at Grand Tower, Illinois. Final Report, Illinois Dept. of Nat. Res., Marion, IL.

Zuanon, J., Bockmann, F. A., and Sazima, I. 2006. A remarkable sand-dwelling fish assemblage from central Amazonia, with comments on the evolution of psammophily in South American freshwater fishes. Neotropical Ichthyology 4(1): 107-118. 
Table 1. A literature review of the substrate size used by western (A. clara) and eastern (A. pellucida) sand darters.

\begin{tabular}{|c|c|c|c|c|c|c|c|c|}
\hline Author(s) & Year & River & $\begin{array}{l}\text { State/ } \\
\text { Province }\end{array}$ & Species & $\begin{array}{l}\text { Size of } \\
\text { Subsrtate }\end{array}$ & Type of Subsrtate & $\begin{array}{l}\text { Study } \\
\text { Type }\end{array}$ & Subsrtate Categories \\
\hline Simon et al. & 1992 & $\begin{array}{l}\text { Black \& Mississippi } \\
\text { Rivers }\end{array}$ & WI & A. clara & - & Coarse Sand & Field & - \\
\hline Daniels & 1993 & Mettawee River & NY & A. pellucida & $0.25-.5 \mathrm{~mm}$ & Sand & Lab & sand $(0.25-0.5 \mathrm{~mm})$, gravel $(1-2 \mathrm{~mm})$, rubble $(8-15 \mathrm{~mm})$ \\
\hline Daniels & 1993 & Mettawee River & NY & A. pellucida & $0.25-.5 \mathrm{~mm}$ & Sand & Field & $\begin{array}{l}\text { Substrate assiagened a numeric value } 1 \text { (silt) to } 5 \text { (boulder) based } \\
\text { on particle size }\end{array}$ \\
\hline Tucker and Cronin & 1996 & $\begin{array}{l}\text { Pool } 26 \text { of the } \\
\text { Mississippi River }\end{array}$ & $\mathrm{MO}, \mathrm{IL}$ & A. clara & - & Sand & Field & - \\
\hline Welsh and Perry & 1998 & Elk River & WV & A. pellucida & $>0.06-2 \mathrm{~mm}$ & Sand & Field & $\begin{array}{l}\text { silt }(0.004-0.06 \mathrm{~mm}) \text {, sand }(>0.06-2 \mathrm{~mm}),>0.2-1 \mathrm{~cm},>1-3 \mathrm{~cm},>3-5 \\
\mathrm{~cm},>5-10 \mathrm{~cm},>10-15 \mathrm{~cm},>15-20 \mathrm{~cm},>20-25 \text {, and }>25 \mathrm{~cm} \text {. }\end{array}$ \\
\hline Facey and O'Brien & 2004 & Poultney River & VT & A. pellucida & 0.12 to $0.54 \mathrm{~mm}$ & Sand & Field & $0.12,0.23,0.54,1.0,1.9,4.1 \mathrm{~mm}$ \\
\hline Drake et al. & 2008 & Thames River & ON & A. pellucida & $0.02-2 \mathrm{~mm}$ & Sand & Field & $\begin{array}{l}\text { clay }(0-0.002 \mathrm{~mm}) \text {, silt }(0.002-0.02 \mathrm{~mm}) \text {, sand }(0.02-2 \mathrm{~mm}) \text {, gravel (2- } \\
40 \mathrm{~mm}) \text {, cobble }(40-256 \mathrm{~mm}) \text {, and boulder }(>256 \mathrm{~mm})\end{array}$ \\
\hline O'Brien and Facey & 2008 & $\begin{array}{l}\text { Poultney \& Winooski } \\
\text { Rivers }\end{array}$ & VT & A. pellucida & $0.24-1.0 \mathrm{~mm}$ & Fine to Large Sand & Field & $0.24-.054 \mathrm{~mm}, 0.55-1.0 \mathrm{~mm}, 1.1-1.9 \mathrm{~mm}, 2.0-4.1 \mathrm{~mm}$ \\
\hline O'Brien and Facey & 2008 & Winooski River & VT & A. pellucida & $0.24-0.54 \mathrm{~mm}$ & Fine to Medium Sand & $\mathrm{Lab}$ & $0.24-.054 \mathrm{~mm}, 0.55-1.0 \mathrm{~mm}, 1.1-1.9 \mathrm{~mm}, 2.0-4.1 \mathrm{~mm}$ \\
\hline Neebling and Quist & 2008 & Cedar River & $\mathrm{IA}$ & A. clara & - & Sand & Field & \\
\hline Tesslar et al. & 2012 & Maumee River & $\mathrm{OH}$ & A. pellucida & $0.125-0.5 \mathrm{~mm}$ & Fine to Medium Sand & Field & $0.063,0.125,0.25,0.5,1.0,2.0 \mathrm{~mm}$ \\
\hline Dextrase et al. & 2014 & Grand \& Thames Rivers & ON & A. pellucida & $0.063-0.5 \mathrm{~mm}$ & Fine to Medium Sand & Field & $\begin{array}{l}<0.063 \text { (silt/clay), } 0.063-2.0 \text { (sand), } 0.063-0.5 \mathrm{~mm} \text { (Fine to Medium } \\
\text { sand), } 2.1 \text { to } 8.0 \mathrm{~mm} \text { (fine gravel), }>8.0 \text { (coarse substratum) }\end{array}$ \\
\hline
\end{tabular}




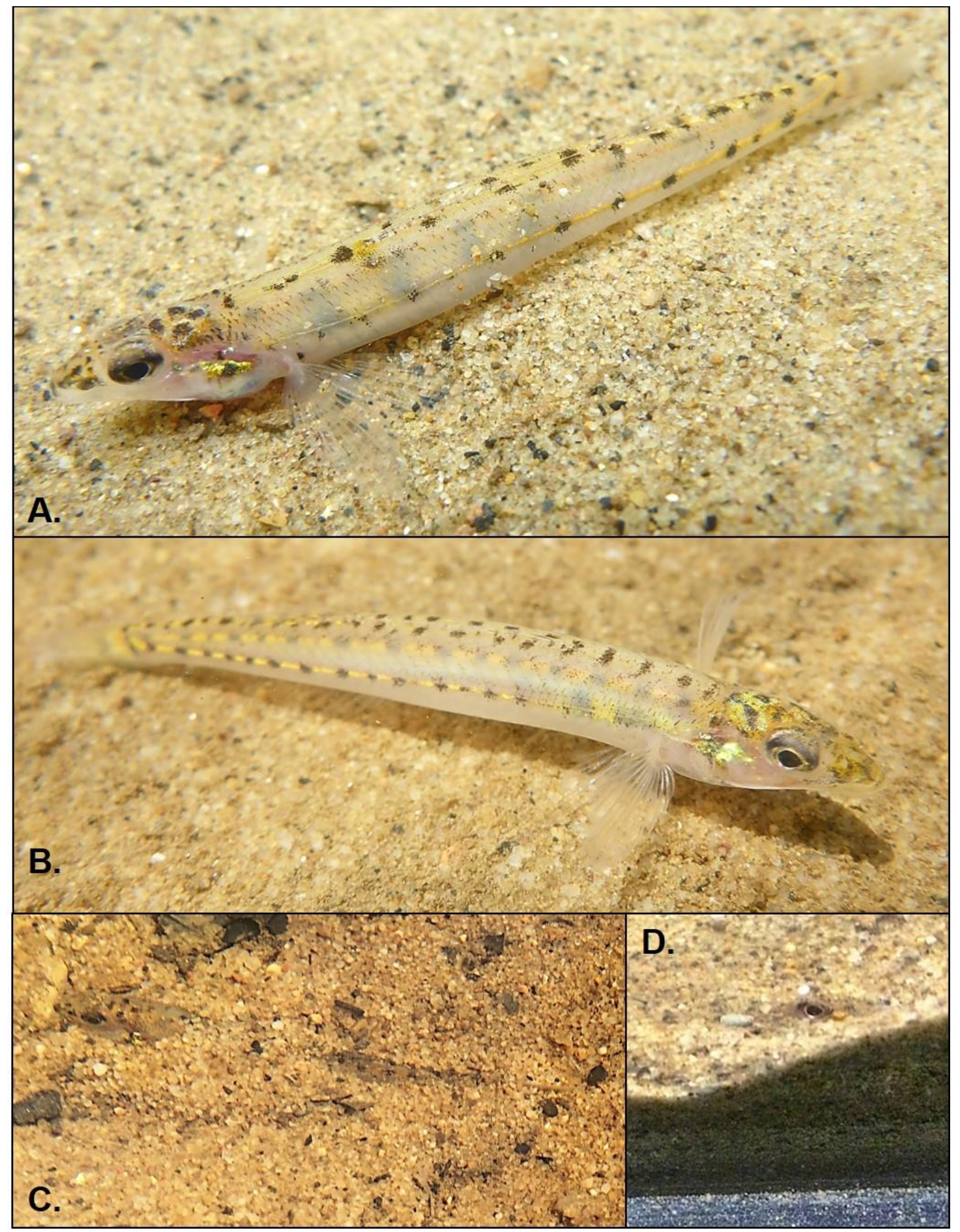

Figure 1.1. A) Eastern sand darter, B) western sand darter, C) partially buried eastern sand darter with cryptic sand-like pigmentation, D) example of sand darter resting behavior 


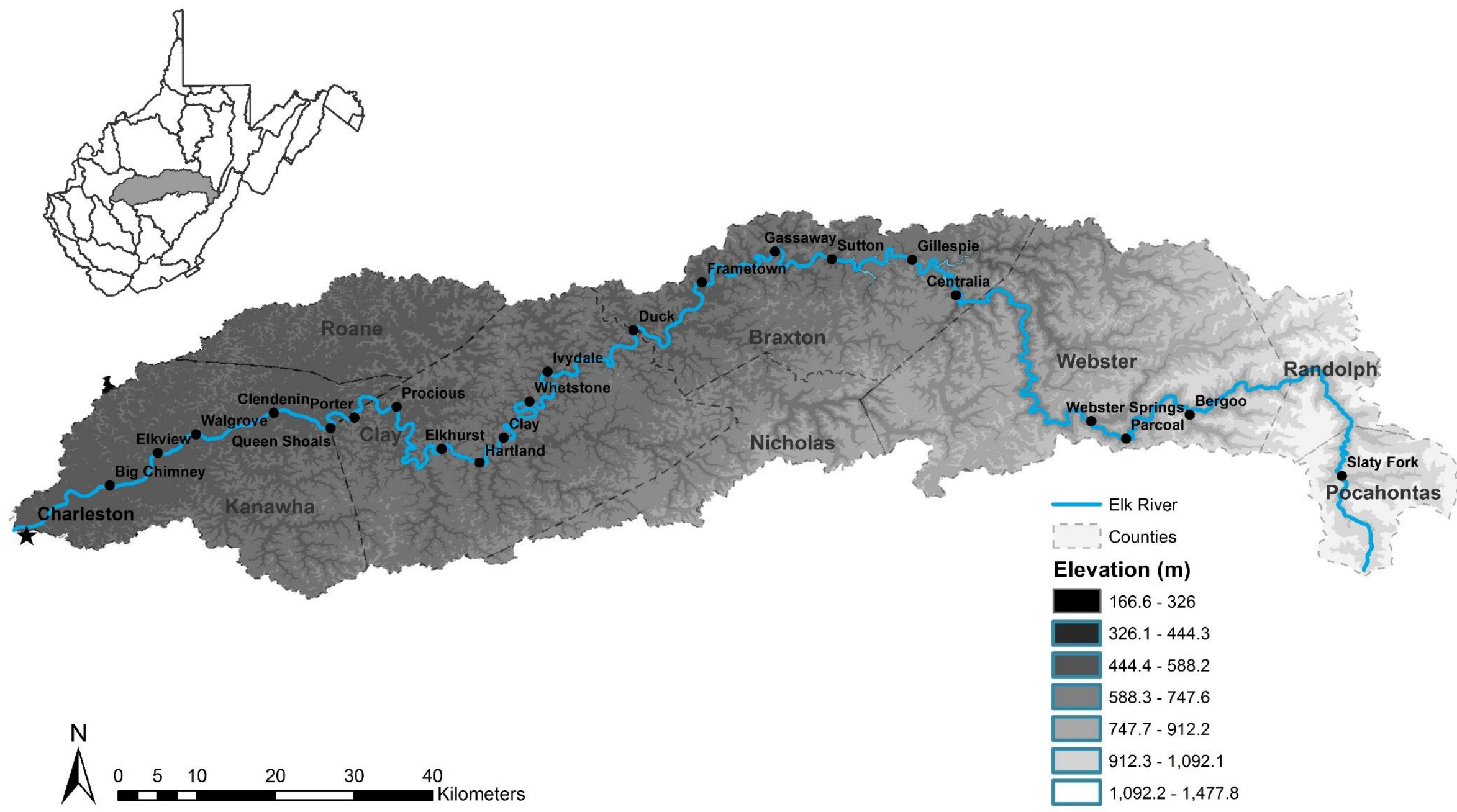

Figure 1.2. Map of the Elk River watershed shaded by elevation with the counties highlighted by a grey dashed line. 


\title{
Chapter 2: Effect of substrate size on sympatric sand darter benthic habitat preferences
}

\begin{abstract}
The western sand darter, Ammocrypta clara, and the eastern sand darter, A. pellucida, are sanddwelling fishes that have undergone range-wide population declines, presumably owing to habitat loss. Habitat use studies have been conducted for the eastern sand darter, but literature on the western sand darter remains sparse. The aim of this study was to evaluate substrate selection of western and eastern sand darters. Individuals for this laboratory study were collected from the Elk River, West Virginia, one of the few remaining rivers where both species occur sympatrically. In the laboratory, two aquaria were divided in half, to create four aquarium sections. Two sections contained six western sand darters in each, while the other two held a combination of both species, three western and three eastern sand darters. Individuals were given the choice to bury into five equally available and randomly positioned substrates: fine sand $(0.12-0.25 \mathrm{~mm})$, medium sand $(0.25-0.5 \mathrm{~mm})$, coarse sand $(0.5-1.0 \mathrm{~mm})$, very coarse sand $(1.0-$ $2.0 \mathrm{~mm})$, and granule gravel $(2.0-4.0 \mathrm{~mm})$. The western sand darter selected for coarse and medium sand, while the eastern sand darter was more of a generalist selecting for fine, medium, and coarse sand. Substrate selection was significantly different $(p=0.02)$ between species in the same environment, where the western sand darter selected for coarser substrate more often compared to the eastern sand darter. Habitat degradation is often a limiting factor for many species of rare freshwater fish, and results from this study suggest that western and eastern sand darters may respond differently to variations in benthic substrate composition.
\end{abstract}

Key words: Ammocrypta, benthic habitat, sand, siltation, substrate

\section{Introduction}

The western sand darter Ammocrypta clara (Jordan \& Meek, 1885) and the eastern sand darter A. pellucida (Putnam, 1863) are the only sympatric species of the genus Ammocrypta (Near et al. 2000), and the Ohio River drainage is currently the sole region where both distributions are known to overlap (Cincotta \& Welsh 2010). Over the years, the number of rivers where each species occurs has declined, presumably in response to degradation of physical stream habitat or water quality (Lachner 1956; Kuehne \& Barbour 1983). Historically, they were sympatric in the Wabash (IN), Green (KY), Cumberland (KY), Kentucky (KY), Big Sandy (KY, WV), and Kanawha (WV) river systems (Williams, 1975; Cincotta \& Welsh 2010). However, 
the western sand darter is presumed to be extirpated from the Licking River in the Kentucky River drainage, the Big Sandy River drainage, and portions of the Wabash River drainage (Williams 1975; Burr \& Warren 1986; Simon 2006). A number of researchers have suggested that siltation of sand habitats has contributed to declines and local extirpations of sand darter populations, and as a result, the western and eastern sand darter have a threatened or critical status throughout most of their ranges (Holm \& Mandrake 1996; Warren et al. 2000; Adams \& Burr 2004; Grandmaison et al. 2004; Driver \& Adams 2014).

Western and eastern sand darters are psammophiles, or organisms that occupy and thrive in sandy environments and possess a combination of specialized traits to flourish in a habitat of predominantly sand (Schaefer et al. 2005; Zuanon et al. 2006; Carvalho et al. 2014). Both species are slender, elongate, slightly translucent with cryptic pigmentation, and are known for burying in sand substrates (Williams 1975). Consequently, siltation of the stream bed may affect the ability of sand darters to bury into sand habitat (Daniels 1989; Holm \& Mandrak 1996; Facey 1998). Since sand darters exhibit strong habitat specificity and are sensitive to habitat alterations, both species are often highly valued as indicators of ecosystem integrity (Grandmaison et al. 2004; Drake et al. 2008). Habitat use and sand grain size preference is well documented for the eastern sand darter (Daniels 1993; Facey \& O’Brien 2004; Drake et al. 2008; O’Brien \& Facey 2008; Tesslar et al. 2012; Dextrase et al. 2014), but literature pertaining to the western sand darter is sparse, and little information is available from areas where the two species are sympatric.

Western and eastern sand darters inhabit medium to large rivers with a moderate current, loose sand and gravel substrates, and spend the majority of the time buried just below the surface of sandy streambeds (Williams 1975; Daniels 1989). Daniels (1993) regarded the eastern sand 
darter as one of the most habitat selective fishes of all freshwater species preferring areas of greater than $90 \%$ sand. In the field and laboratory setting, eastern sand darters exclusively associated with sand substrates, while water velocity, depth, and distance from the bank had little to no effect on the distribution of individuals (Daniels 1993). Laboratory studies that investigated eastern sand darter substrate use reported individuals generally used medium (0.25-0.5 mm) sized particles (Daniels 1993; O’Brien \& Facey 2008). Furthermore, field surveys revealed this species was commonly detected in sand comprised of fine to medium $(0.12-0.5 \mathrm{~mm})$ particles, while few individuals were detected in areas where the particle size was larger than $1.0 \mathrm{~mm}$ (Facey \& O’Brien 2004; Tesslar et al. 2012; Dextrase et al. 2014). Pflieger (1971) noted that in Missouri the western sand darter avoided strong currents, inhabiting shallow backwater areas, as well as quiet margins of a drainage canal at depths up to $1.5 \mathrm{~m}$. Simon et al. (1992) observed the western sand darter spawning and described the habitat as an area on the downstream side of an island with a slow current over coarse sand.

Although sand grain size appears to be an integral life history component of the western sand darter, little information is available on substrate size preference for this species. Additionally, little research exists documenting habitat selection behavior where both the western and eastern sand darter are sympatric. This study sought to examine western and eastern sand darter benthic habitat preferences in laboratory aquaria to 1) determine substrate size selection preferences for the western sand darter, 2) evaluate substrate selection in an environment where the two species are sympatric, and 3) assess if substrate selection differs significantly between the two species.

\section{Methods and materials}




\section{Fish collection and aquaria setup}

A total of 20 western sand darters and 20 eastern sand darters were collected from the lower Elk River during October 2015 and transported to the laboratory in an aerated cooler (Fig. 1.1). For collection, a straight $1.5 \times 3 \mathrm{~m}$ seine with $3 \mathrm{~mm}$ mesh was used in wadable areas of the river, including upstream and downstream parallel seine hauls and perpendicular hauls pulled into shore (O’Brien \& Facey 2008; Driver \& Adams 2013). In the laboratory, fish were placed initially in a $473 \mathrm{~L}(183 \mathrm{~cm} \times 46 \mathrm{~cm} \times 56 \mathrm{~cm})$ glass aquaria and allowed to acclimate prior to the start of the substrate selection trials. Water conditions within each tank were maintained by a sequence pump $(2.6 \mathrm{~L} / \mathrm{min})$ recirculating water from a $379 \mathrm{~L}$ sump to the aquaria. Water quality was controlled with carbon filters, bio balls, and freshwater substitutions. The room temperature within the laboratory during late fall remained between $15-17^{\circ} \mathrm{C}$. Photoperiod was maintained with wide spectrum fluorescent plant bulbs and an electric timer (12 h light, $12 \mathrm{~h}$ dark). The fish were fed frozen bloodworms (chironomids) every other day throughout the experiment. On a day with a substrate trial the fish were fed after the experiment.

\section{Experimental design}

The experimental design was similar to other aquaria based fish habitat use, burying behavior, and habitat selection studies (Daniels 1989, 1993; Smith et al. 2011). The sand darters were allowed to acclimate in the laboratory aquaria for at least seven days prior to the start of the experiment. After the acclimation period, a subset of individuals were placed into the experimental aquarium sections. Two $473 \mathrm{~L}(183 \mathrm{~cm}$ x $46 \mathrm{~cm}$ x $56 \mathrm{~cm})$ glass aquaria were divided in half by a mesh barrier, thus creating a total of four aquarium sections of equal size. For each experiment, six western sand darters were placed in one aquarium section, and another 
six western sand darters were placed in a second aquarium section. Additionally, three western sand darters and three eastern sand darters were placed in the third aquarium section, and another three western sand darters and three eastern sand darters were placed in the fourth aquarium section.

Each aquarium section contained five plastic containers $(24.9 \times 15.7 \times 5.3 \mathrm{~cm})$ filled with approximately $5 \mathrm{~cm}$ of substrate: fine sand $(0.125-0.25 \mathrm{~mm})$, medium sand $(0.25-0.5 \mathrm{~mm})$, coarse sand $(0.5-1.0 \mathrm{~mm})$, very coarse sand $(1.0-2.0 \mathrm{~mm})$, and granule gravel $(2.0-4.0 \mathrm{~mm})$ (Wentworth 1922). Sand for this study was collected primarily from the Elk River (90\%), as well as a later addition of aquaria sand (CaribSea Super Naturals Aquarium sand; 10\%) to supplement the finer sand that was lost in suspension between trials. The sand for the substrate trials was sifted using a Gilson $20.3 \mathrm{~cm}$ (8 in) sieve Shaker $(115 \mathrm{~V} / 60 \mathrm{~Hz})$ with U.S. Standard brass sieves. Finer substrate was not used since particles smaller than fine sand may not remain settled due to fish activity and current from the water filter (O’Brien \& Facey 2008).

At the start of each trial fish were released into an aquarium section and given a choice of five equally available and randomly positioned substrate types. A total of 15 trials were conducted with each trial lasting $48 \mathrm{hrs}$. At the end of each trial, the substrate containers were capped and transferred individually to a separate container, where the darters were gently removed from the sand, identified to species, and enumerated. We were concerned that an idealfree distribution effect (i.e., Fretwell \& Lucas 1969) could prevent six individuals in an aquarium section from using the same substrate container. A pilot study, however, found that 10 individual fish would readily bury in an individual substrate container. It is also possible that another density-dependent effect occurred, where an individual was attracted to a substrate container because it was being used by one or more individuals. Our study design, however, did not allow 
for measurement of this type of effect, and no known literature exists suggesting this type of social attraction. Overall, our sample size of fish was low because of difficulty of detecting the western sand darter and the conservation status associated with the western sand darter (WVDNR 2015).

\section{Data analysis}

To evaluate resource selection, the log-likelihood ratio test was used to determine if sand darter substrate selection was in proportion to its availability (i.e., random or nonrandom) within the experimental aquaria (Manly et al. 2002). The data for the western sand darter only aquaria and the combined species aquaria were pooled across the two tanks. Selection ratios were then calculated following Manly et al. (2002) to evaluate substrate size preference. This method assumes there is no unique identification of individuals, the proportion of resource categories are known, and a random sample of used resources is taken. The selection ratio for a given group is the proportion of used units in a category over the proportion of available categories (Manly et al. 2002). Selection ratio values greater than one indicate selection, and values less than one indicate avoidance (Manly et al. 2002). Bonferroni 95\% confidence intervals were calculated for each selection ratio and were considered statistically significant when the interval did not contain the value of one (Manly et al. 2002). Furthermore, pairwise comparisons with Bonferroni $95 \%$ confidence intervals were generated to assess differences between grain size selections. The substrate category granule gravel was removed from all statistical analyses because neither species utilized this habitat type.

A multinomial logistic regression model was used to compare if substrate size selection differed significantly between the two species of sand darters (Hosmer \& Lemeshow 2000). 
Following Smith et al. (2011) the response variable was substrate type and the explanatory variables were species and trial. Deviance statistics were used to determine if substrate selection significantly differed between the western and eastern sand darters. Furthermore, odds ratios were assessed to evaluate the effect of species on substrate selection. Odds are the ratio between the probability of using or not using a substrate type. The category 'fine sand' was designated as our reference category for the odds ratio. The reference category is an arbitrary designation and should be one which makes the subsequent inference the simplest or the most meaningful (Roger \& White 2007). Wald confidence intervals were estimated for the odds ratios to further examine significant differences between substrate size preferences. Wald's confidence intervals that did not contain the value of one were considered to be statistically significant (Hosmer \& Lemeshow 2000). The selection ratios, Bonferroni $95 \%$ confidence intervals, and pairwise comparisons were calculated using statistical software R (version 3.2.3), and the multi-logit model, odds ratios, and Wald's confidence intervals were generated using SAS (version 9.4).

\section{Results}

\section{Western sand darter microhabitat use}

The log-likelihood ratio revealed that substrate selection was not in proportion to its availability $(p=0.04)$, indicating that sand grain size selection in the aquaria was nonrandom. Across the 15 trials there were 174 instances of western sand darters found buried in the substrate, while there were 6 instances in which individuals were found above the surface of the sand. Western sand darters primarily buried in coarse (33\%) and medium sand (28\%), followed by fine (20\%) and very coarse (19\%) sand. No individuals were detected in granule gravel. Western sand darters selected for coarse $\left(\hat{\mathrm{W}}_{\mathrm{i}}=1.31\right)$ and medium $\left(\hat{\mathrm{W}}_{\mathrm{i}}=1.10\right)$ sand, and selected 
against fine $\left(\hat{\mathrm{W}}_{\mathrm{i}}=0.81\right)$ and very coarse $\left(\hat{\mathrm{w}}_{\mathrm{i}}=0.78\right)$ sand (Table 2.1). However, the Bonferroni 95\% confidence intervals did not indicate significant preference for or against a specific substrate category (Table 2.1). The substrate selection ratios were further examined with a pairwise comparison with Bonferroni $95 \%$ confidence intervals, which revealed that coarse sand was selected with a higher probability compared to very coarse sand $(p=0.05)$ and coarse sand was selected over fine sand but not significantly $(p=0.08)$ (Table 2.2). Although the results were not all statistically significant they suggest that western sand darters exhibited a tendency to select for sand habitat ranging in size from medium to coarse grains (0.25-1.0 mm) (Fig. 2.2).

\section{Sympatric microhabitat use}

In the combined species aquaria, western and eastern sand darters each displayed nonrandom substrate selection $(p<0.01)$. Across the 15 trials, western sand darters were found buried 88 times and eastern sand darters were found buried 84 times. In contrast, western sand darters were detected above the substrate just 2 times, and eastern sand darters were detected above the substrate just 6 times. Western sand darters primarily buried in coarse (39\%) and medium (32\%) sand, while eastern sand darters primarily selected medium (34\%) and fine (33\%) sand. To examine preference or avoidance, selections ratios were calculated for each species. Western sand darters significantly selected for coarse sand, while significantly selecting against fine and very coarse sand (Table 2.1). Eastern sand darters exhibited a preference for fine, medium, and coarse sand, while significantly selecting against very coarse sand (Table 2.1). The pairwise comparisons revealed that western sand darters had a significantly higher probability of selecting coarse sand over fine and very coarse sand, as well as medium sand over very coarse 
sand (Table 2.2). In contrast, the eastern sand darter had a significantly higher probability of selecting fine, medium, and coarse sand over very coarse sand (Table 2.2).

Comparing the selection ratios, western and eastern sand darters each demonstrated a strong preference for medium sand. However, eastern sand darters also selected for fine sand ( $\hat{\mathrm{W}}_{\mathrm{i}}$ $=1.33$ ), whereas western sand darters selected against fine sand $\left(\hat{\mathrm{w}}_{\mathrm{i}}=0.64\right)($ Fig. 2.2). The multinomial logistic regression demonstrated that substrate size selection differed significantly between the sand darter species for at least one substrate category $(p=0.02)$. The effect of sand darter species on substrate selection was further evaluated using odds ratios and Wald conference intervals, with the reference category fine sand. The odds ratios demonstrated significant effect for species on coarse (odds ratio 3.26, CI [1.31, 8.13]) and very coarse (odds ratio 5.25, CI [1.50, 18.40]) sand. No species effect was found for medium sand (odds ratio 1.97, CI [0.81, 4.83]). Thus, western sand darters compared to eastern sand darters are 5.25 times more likely to select very coarse sand over fine sand and 3.26 times more likely to select coarse sand over fine sand. Overall, the western sand darter had a higher probability of selecting medium, coarse, and very coarse sand over fine sand compared to the eastern sand darter.

\section{Discussion}

Our aquaria based study represents the first evaluation of sand grain size preference for the western sand darter and the first investigation of substrate selection in a region where the two species of sand darters are sympatric. The western and eastern sand darters are habitat specialists, occupying areas that consist of predominantly sand (Daniels 1993; Simon et al. 1992). Western sand darters preferred coarse to medium sand, while substrate preference of eastern sand darters was similar to results from previous studies, with the species preferring fine to medium sand 
grains and coarse sand to a lesser extent (e.g., Daniels 1993; Facey \& O'Brien 2004). In general, western sand darters selected for a narrower range of substrate sizes compared to the eastern sand darter, and habitat use overlap occurred most often in the medium sand category. This study was contingent upon five designated substrate types that were similar to previous sand darter habitat use studies (Daniels 1993; O’Brien \& Facey 2008) and represented a range of benthic habitats both species may encounter (Welsh \& Perry 1998; Facey \& O’Brien 2004; Tesslar et al. 2012). Habitat use in the field could vary compared to the aquaria-based study, but our results demonstrated that each sand darter species exhibited nonrandom selection of substrate types, indicating that a certain benthic habitat was preferred compared to the other available sizes.

The western sand darter was recently discovered in the Elk River, where it was previously misidentified as the eastern sand darter (Cincotta \&Welsh 2010). After the discovery, eastern sand darter museum specimens collected from 1986 to 2006 were reexamined, and a total of 17 western sand darters were documented in the lower $36 \mathrm{rkm}$ of the Elk River, and all cooccurred with the eastern sand darter. Therefore, the two species are sympatric within the lower $36 \mathrm{rkm}$ of the Elk River, whereas the eastern sand darter can be detected up to $135 \mathrm{rkm}$ from the mouth (Welsh \& Perry 1998; Cincotta \& Welsh 2010; Fig. 2.1). The sand darters differences in substrate selection may influence the western sand darter's limited range in the Elk River. The restricted range of the western sand darter compared to the eastern sand darter in the Elk River is of conservation concern, since the Elk River is the only known location in West Virginia where the western sand darter persists, and represents the southeastern extent for both species (Cincotta \& Welsh 2010).

Habitat availability below the Sutton Dam (lower $190 \mathrm{rkm}$ ) is potentially limited for the western sand darter compared to its more habitat generalist sister species. As a result, the quality 
of a certain sand habitat likely varies depending upon its position in the river, which is ultimately controlled by fluvial geomorphology, as well as soil development and vegetation (e.g., Vannote et al. 1980; Jackson et al. 2001; Wang et al. 2011). Given that western sand darters are restricted to the lower $36 \mathrm{rkm}$ of the Elk River, this implies that this section of the river has more suitable habitat for the western sand darter (i.e., higher proportions of medium to coarse sand). Thus, larger more contiguous sand patches are presumably more available in the lower reaches of the Elk River, where additional sediment is added to the system from contributing tributaries. Furthermore, the maintenance of these sandy depositional areas are likewise influenced by the presence of the Sutton Dam, which impounds a large $6 \mathrm{~km}^{2}$ reservoir. The dam alters natural flow regimes and changes scouring and depositional patterns (e.g., Baxter 1977; Power et al. 1996; Poff \& Hart 2002).

The aquaria-based experiment provided information on habitat use of two species of sand-dwelling darters, data that can be challenging to obtain in the field because of their burying behavior. Preference for larger substrate sizes may indicate that western sand darters are more sensitive to fine sediment deposition compared to eastern sand darters. Habitat selection study results indicate where a species is likely to find a set of conditions within their physiological tolerance (Rice 2005). Thus, the siltation of the sand darters preferred habitat is potentially more limiting for the western sand darter and may be a contributing factor to the western sand darters sporadic distribution in the Elk River and the Ohio River drainage. For instance, the eastern sand darter persists in the Licking (KY), Tug (KY, WV), and Wabash (IN) rivers, whereas the western sand darter is presumed to be extirpated (Burr \& Warren 1986; Simon 2006). Likewise, in the Wabash River the eastern sand darter has been reported as increasing in distribution and abundance, whereas the western sand darter remains undetected or extirpated from the main 
channel (Simon 2006). Furthermore, in Indiana the western sand darter is a species of special concern, whereas the eastern sand darter was delisted following a statewide survey of the species (INDNR 2004). Similar research could be conducted in other rivers that contain western sand darters, which would further document sand grain size preference across the range of this species.

The type of rivers that western and eastern sand darters occupy (i.e., moderately large with a low gradient) are often located in landscapes that also attract urban development, industrialization, and agriculture. Therefore, these species face potential impacts from land use activities that increase the amount of siltation in the watershed; however, with improved land use practices, and other efforts to minimize impacts to watersheds, it is possible to protect and enhance sand darter populations (Grandmaison et al. 2004; COSWIC 2009; Tessaler et al. 2012). There are a number of places where the eastern sand darter was absent for more than 50 years and have since recolonized improved stretches of rivers (Tesslar et al. 2012; Hopkins \& Zimmerman 2014). As a result, understanding habitat use preferences can aid in the recovery of both species. Further information gained from sand darter habitat use studies may provide insight into the health and overall quality of an aquatic ecosystem, especially in large river systems that are impacted by urban development and intensive agriculture.

\section{Acknowledgements}

The authors appreciate the field and laboratory assistance provided by J. Aldinger, B. Crabill, K. Lambert, and B. Tierney. Additional thanks to M. Strager of West Virginia University and D. Cincotta from the West Virginia Division of Natural Resources. This study was performed under the auspices of West Virginia University IACUC protocol 15-0801. Any use of trade, firm, or 
product names is for descriptive purposes only and does not imply endorsement by the U.S. Government.

\section{Literature Cited}

Adams GL, Burr BM. 2004. Conservation assessment for the eastern sand darter, Ammocrypta pellucida. Report submitted to the Hoosier National Forest, USDA Forest Ser, Bedford, IN.

Baxter RM. 1977. Environmental effects of dams and impoundments. Annu Rev Ecol Syst, 255283.

Burr BM, Warren ML. 1986. A distributional atlas of Kentucky fishes. Ky Nature Preserv Comm Sci Tech Ser 4.

Carvalho MS, Zuanon J, Ferreira EJ. 2014. Diving in the sand: the natural history of Pygidianops amphioxus (Siluriformes: Trichomycteridae), a miniature catfish of Central Amazonian streams in Brazil. Environ Biol Fish. 97(1):59-68.

Charlton R. 2007. Fundamentals of fluvial geomorphology. Routledge. New York, NY.

Cincotta DA, Welsh SA. 2010. Discovery of Ammocrypta clara (western sand darter) in the Upper Ohio River of West Virginia. Am Mid Nat. 163(2):318-325.

COSEWIC 2009. Committee on the Status of Endangered Wildlife in Canada assessment and status report on the eastern sand darter Ammocrypta pellucida, Ontario populations and Quebec populations. Ottawa, Canada.

Daniels RA. 1989. Significance of burying in Ammocrypta pellucida. Copeia 1989:29-34.

Daniels RA. 1993. Habitat of the eastern sand darter, Ammocrypta pellucida. J Freshw Ecol. $8: 287-295$. 
Dextrase AJ, Mandrak NE, Schaefer JA. 2014. Modelling occupancy of an imperiled stream fish at multiple scales while accounting for imperfect detection: implications for conservation. Freshw Biol. 59(9):1799-1815.

Drake DAR, Power M, Koops MA, Doka SE, Mandrak NE. 2008. Environmental factors affecting growth of eastern sand darter (Ammocrypta pellucida). Can J Zool. 86:714-722.

Driver LJ, Adams GL. 2013. Life History and Spawning Behavior of the western sand darter (Ammocrypta clara) in Northeast Arkansas. Am Mid Nat. 170(2):199-212.

Facey DE. 1998. The status of the eastern sand darter, Ammocrypta pellucida, in Vermont. Can Field Nat. 112(4):596-601.

Facey DE, O'Brien SM. 2004. Influence of substrate composition on distribution of eastern sand darters (Ammocrypta pellucida) in the Poultney River. Pages 291 - 297 in T. O. Manley, P. L. Manley, and T. B. Mihuc, editors. Lake Champlain: partnerships and research in the new millennium. Kluwer Academic/Plenum Publishers, New York, NY.

Fretwell SD, Lucas HJ Jr. 1969. On territorial behavior and other factors influencing habitat distribution in birds. Acta Biotheor. 19(1):37-44.

Grandmaison D, Mayasich J, Etnier D. 2004. Eastern sand darter status assessment. US Fish and Wildlife Ser., Region, 3. NRRI Tech Rep No. NRRI/TR-2003/40.

Gutreuter S, Bartels AD, Irons K, Sandheinrich MB. 1999. Evaluation of the flood-pulse concept based on statistical models of growth of selected fishes of the Upper Mississippi River system. Can J Fish Aquat Sci. 56:2282-2291.

Holm E, Mandrak NE. 1996. The status of the eastern sand darter, Ammocrypta pellucidia, in Canada. Can Field Nat. 110(3):462-469. 
Hopkins RL, Zimmerman B. 2014. First observation of the eastern sand darter (Ammocrypta pellucida) in Raccoon Creek (Ohio River Basin) in Southeastern Ohio in 57 Years. Northeastern Nat. 21(1):N13-N17.

Hosmer DW, Lemeshow S. 2000. Applied logistic regression. Wiley, Hoboken.

INDNR 2004. Eastern sand darter is removed from state special concern list. Wildlife Diversity Sect Annu Rep, Division of Fish and Wildlife Indiana Dep Nat Res., pp.23.

Knighton, D. 1998. Fluvial forms and processes a new perspective. Holder Arnold London, UK.

Kuehne RA, Barbour RW. 1983. The American darters. The Univ Press of Kansas. 177 pp.

Jackson DA, Peres-Neto PR, Olden JD. 2001. What controls who is where in freshwater fish communities the roles of biotic, abiotic, and spatial factors. Can J Fish Aquat Sci 58(1):157-170.

Junk WJ, Bayley PB, Sparks RE. 1989. The flood pulse concept in river-floodplain systems. Can Spec Pub Fish Aquat Sci. 106(1):110-127.

Lachner EA. 1956. The changing fish fauna of the upper Ohio River basin, p. 64-78. In: Man and the waters of the upper Ohio basin, University of Pittsburgh, Pymatuning Laboratory of Ecology, Spec Pub 1, Pittsburgh.

Lin DSC, Caramaschi TP. 2005. Responses of the fish community to the flood pulse and siltation in a floodplain lake of the Trombetas River, Brazil. Hydrobiologia 545:75-91.

Manly BFJ, McDonald LL, Thomas DL, McDonald TL, Erickson WP. 2002. Resource selection by animals. Kluwer Academic Publishers, Dordrecht.

Near TJ, Porterfield JC, Page LM. 2000. Evolution of cytochrome b and the molecular systematics of Ammocrypta (Percidae: Etheostomatinae). Copeia 2000(3):701-711. 
O'Brien SM, Facey DE. 2008. Habitat use by the eastern sand darter, Ammocrypta pellucida, in two Lake Champlain tributaries. Can Field Nat. 122(3):239-246.

Pflieger WL. 1971. A distributional study of Missouri fishes. Univ Kans publ, Mus Nat Hist. 20:225-570.

Poff NL, Hart DD. 2002. How dams vary and why it matters for the emerging science of dam removal. BioSci. 52(8):659-668.

Power ME, Dietrich WE, Finlay JC. 1996. Dams and downstream aquatic biodiversity: potential food web consequences of hydrologic and geomorphic change. Environ Manag. 20(6):887-895.

Rice JC. 2005. Understanding fish habitat ecology to achieve conservation. J Fish Biol. $67(\mathrm{sB}): 1-22$.

Rogers KB, White GC. 2007. Analysis of movement and habitat use from telemetry data. Analysis and interpretation of freshwater fisheries data. American Fisheries Society, Bethesda, Maryland, 625-676. eds Guy, C.S. and Brown M.L. pp. 625-676.

Schaefer SA, Provenzano F, de Pinna M, Baskin JN. 2005. New and noteworthy Venezuelan Glanapterygine catfishes (Siluriformes, Trichomycteridae), with discussion of their biogeography and psammophily. Am Mus Novitates. 3496:1-27.

Simon TP, Tyberghein EJ, Scheidegger KJ, Johnston CE. 1992. Descriptions of protolarvae of the sand darters (Percidae: Ammocrypta and Crystallaria) with comments on systematic relationships. Ichthyol Expl Freshw. 3:347-358.

Simon TP. 2006. Biodiversity of fishes in the Wabash River: status, indicators, and threats. In: Proceedings of the Indiana Academy of Science 115(2):136-148. 
Smith DM, Welsh SA, Turk PJ. 2011. Selection and preference of benthic habitat by small and large ammocoetes of the least brook lamprey (Lampetra aepyptera). Environ Bio Fish. 91(4):421-428.

Tessler NR, Gottgens JF, Kibbey MR. 2012. The first observations of the eastern sand darter, Ammocrypta pellucida (Agassiz), in the Ohio portion of the Maumee River mainstem in sixty-five years. Am Mid Nat. 167(1):198-204.

Vannote RL, Minshall GW, Cummins KW, Sedell JR, Cushing CE. 1980. The river continuum concept. Can J Fish Aquat Sci. 37(1):130-137.

Wang L, Lyons J, Rasmussen P, Seelbach P, Simon T, Wiley M, Kanehl P, Baker E, Niemela S, Stewart PM. 2003. Watershed, reach, and riparian influences on stream fish assemblages in the Northern Lakes and Forest Ecoregion, USA. Can J Fish Aquat Sci. 60(5):491-505.

Warren Jr ML, Burr BM, Walsh SJ, Bart Jr HL, Cashner RC, Etnier DA, Ross ST. 2000.

Diversity, distribution, and conservation status of the native freshwater fishes of the southern United States. Fish. 25(10):7-31.

Welsh SA, Perry SA. 1998. Habitat partitioning in a community of darters in the Elk River, West Virginia. Environ Biol Fish. 51:411-419.

Welsh SA, Smith DM, Taylor ND. 2013. Microhabitat use of the diamond darter. Ecol Freshw Fish. 22:587-595.

Wentworth CK. 1922. A scale of grade and class terms for clastic sediments. J Geol. 30:377-392. Williams JD. 1975. Systematics of the percid fishes of the subgenus Ammocrypta, genus Ammocrypta, with descriptions of two new species. Bull. Al Mus Nat Hist. 1:1-56. WVDNR, 2015. West Virginia State Wildlife Action Plan, West Virginia Division of Natural Resources, Draft June 10, 2015, Elkin, WV. 
Zuanon J, Bockmann FA, Sazima I. 2006. A remarkable sand-dwelling fish assemblage from central Amazonia, with comments on the evolution of psammophily in South American freshwater fishes. Neotrop Ichthyol. 4(1):107-118. 
Table 2.1. Substrate selection ratio estimates and the Bonferroni confidence intervals for the western sand darter only aquaria and sympatric species aquaria. Selection ratio values > 1 indicate selection, while values $<1$ indicate avoidance. An asterisk * indicates significant selection or avoidance.

\begin{tabular}{lccc}
\hline Substrate Type & Selection Ratio & Lower Cl & Upper Cl \\
& & & \\
\hline Western sand darter (single species aquaria) & & & \\
$\quad$ Fine Sand & 0.81 & 0.532 & 1.078 \\
$\quad$ Medium Sand & 1.10 & 0.798 & 1.408 \\
$\quad$ Coarse Sand & 1.31 & 0.992 & 1.628 \\
$\quad$ Very Coarse Sand & 0.78 & 0.513 & 1.051 \\
& & & \\
Western sand darter (sympatric aquaria) & & & \\
$\quad$ Fine Sand & 0.64 & 0.287 & $0.985^{*}$ \\
$\quad$ Medium Sand & 1.27 & 0.827 & 1.719 \\
$\quad$ Coarse Sand & 1.55 & 1.079 & $2.011^{*}$ \\
$\quad$ Very Coarse Sand & 0.55 & 0.218 & $0.872^{*}$ \\
& & & \\
Eastern sand darter (sympatric aquaria) & & & \\
$\quad$ Fine Sand & 1.33 & 0.872 & 1.794 \\
$\quad$ Medium Sand & 1.38 & 0.915 & 1.847 \\
$\quad$ Coarse Sand & 1.05 & 0.618 & 1.478 \\
$\quad$ Very Coarse Sand & 0.24 & 0.007 & $0.469^{*}$ \\
\hline
\end{tabular}


Table 2.2. Pairwise comparison with Bonferroni confidence intervals for the western sand darter only and combined species aquaria. An asterisk * indicates significant selection. The substrate categories used for the study included fine sand (FS), medium sand (MS), coarse sand (CS), and very coarse sand (VCS).

$\overline{\text { Substrate comparison } \quad \text { Lower } \mathrm{Cl} \text { Upper } \mathrm{Cl} p \text {-value }}$

Western sand darter (single species aquaria)

CS vs. FS

CS vs. MS

FS vs. MS

CS vs. VCS

FS vs. VCS

MS vs. VCS

$\begin{array}{lll}-0.039 & 1.032 & 0.080\end{array}$

$\begin{array}{lll}-0.349 & 0.722 & 1.000\end{array}$

$\begin{array}{lll}-0.846 & 0.226 & 0.710\end{array}$

$\begin{array}{lll}-0.002 & 1.069 & 0.051\end{array}$

$\begin{array}{lll}-0.498 & 0.573 & 1.000\end{array}$

$\begin{array}{lll}-0.188 & 0.883 & 0.489\end{array}$

Western sand darter (sympatric aquaria)

CS vs. FS

CS vs. MS

FS vs. MS

CS vs. VCS

FS vs. VCS

$\begin{array}{lll}0.263 & 1.496 & 0.002^{*}\end{array}$

$\begin{array}{lll}0.275 & 0.892 & 1.000\end{array}$

MS vs. VCS

$\begin{array}{lll}-0.504 & 0.012 & 0.058\end{array}$

$0.978 \quad 1.594<0.01^{*}$

$\begin{array}{lll}0.098 & 0.714 & 1.000\end{array}$

$\begin{array}{lll}0.702 & 1.318 & 0.017^{*}\end{array}$

Eastern sand darter (sympatric aquaria)

CS vs. FS

$\begin{array}{lll}-0.948 & 0.565 & 1.000\end{array}$

CS vs. MS

$\begin{array}{lll}-1.043 & 0.470 & 1.000\end{array}$

FS vs. MS

$\begin{array}{lll}-0.852 & 0.661 & 1.000\end{array}$

CS vs. VCS

$0.1351 .647 \quad 0.013^{*}$

FS vs. VCS

$0.226 \quad 1.838 \quad 0.001^{*}$

MS vs. VCS

$0.421 \quad 1.934<0.01^{*}$




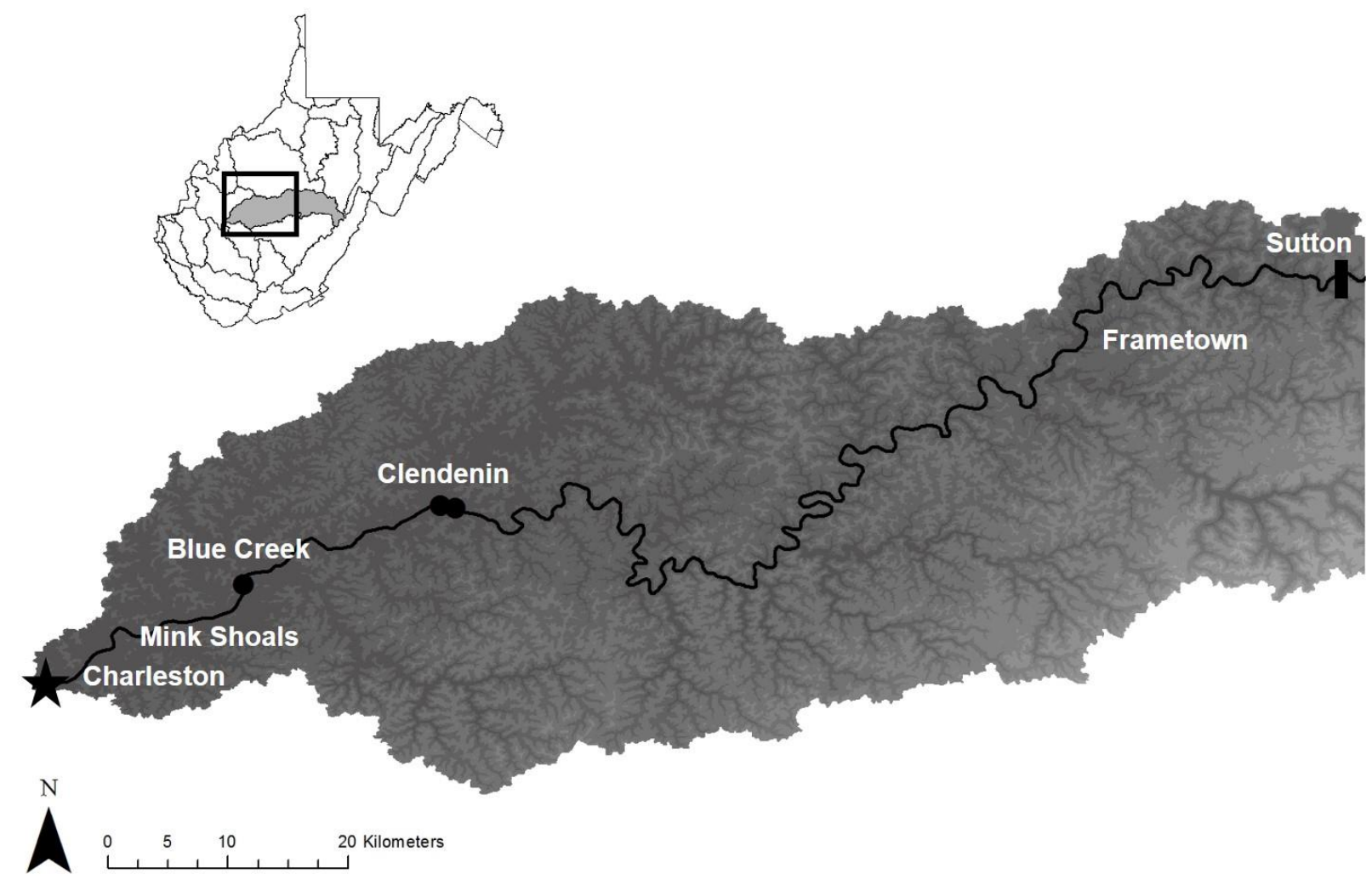

Figure 2.1. Map of the lower $190 \mathrm{rkm}$ of the Elk River watershed shaded by elevation below the dam (black rectangle) in Sutton, WV. Western sand darters have been detected from Mink Shoals to Clendenin and eastern sand darters have been detected from Mink Shoals to Frametown. The black circles represent the three sand darter collection locations. 


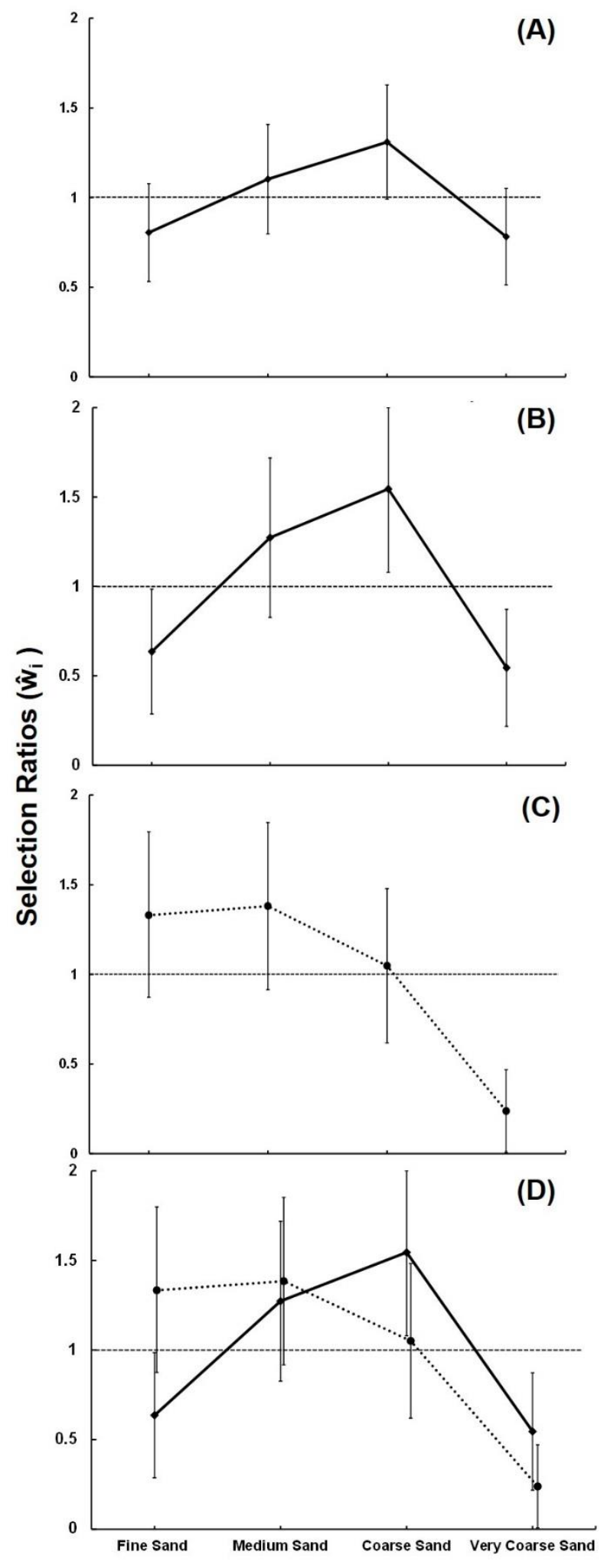

Figure 2.2. Western sand darter only experiment (A), western sand darters from the combined aquarium (B), eastern sand darters from the combined aquaria (C), and combined selection results (D). Values above the dashed line at one indicate selection and values below indicate avoidance. Bonferroni $95 \%$ confidence intervals that do not contain the value of one are considered to be statistically significant. 


\title{
Chapter 3: A multiscale investigation of habitat use and within-river distribution of sympatric sand darter species
}

\begin{abstract}
The western sand darter Ammocrypta clara, and eastern sand darter Ammocrypta pellucida are sand-dwelling fishes of conservation concern. Past research has emphasized the importance of studying individual populations of conservation concern, while recent research has revealed the importance of incorporating landscape-level processes that structure habitat mosaics and local populations. We examined habitat use and distributions of western and eastern sand darters in the lower Elk River of West Virginia. At the mesohabitat scale, western sand darters were detected in sandbars with greater area, higher proportions of coarse grain sand and faster bottom current velocity, while the eastern sand darter was more of a generalist using a wider range of sandbar habitats. A landscape-level analysis supported drainage area as a predictor for both species, while sinuosity also contributed to the western sand darter's habitat suitability. Sandbar quality (area, grain size, and velocity) and fluvial geomorphic variables (drainage area and sinuosity) are likely key driving factors structuring sand darter distributions in the Elk River. This multiscale study of species distribution and habitat use is unique, given that only a few sympatric populations are known of western and eastern sand darters.
\end{abstract}

Key words: Ammocrypta, habitat, maximum entropy, sand, species distribution models

\section{Introduction}

Western sand darters Ammocrypta clara (Jordan \& Meek, 1885) and eastern sand darters A. pellucida (Putnam, 1863) are slender, benthic, sand-dwelling fishes in the family Percidae

(Williams 1975). These two species are the only sympatric species of the genus Ammocrypta (Near et al. 2000), and are solely sympatric within the Ohio River drainage (Cincotta \& Welsh 2010). Over the years, the number of rivers within the Ohio River drainage where both species occur has declined, possibly owing to adverse anthropogenic practices, which degrade and often fragment instream habitat (Kuehne \& Barbour 1983). As a result, western and eastern sand darters have a threatened or critical status in the majority of the states where each species occur (Warren et al. 2000; Grandmaison et al. 2004; Driver \& Adams 2013), and the western sand 
darter is extremely rare in the southeastern United States (Kuehne \& Barbour 1983; Page \& Burr 2011). Despite these far-reaching declines, a general lack of information exists on the life history and ecology of the western sand darter (Driver \& Adams 2013), especially from areas where it is sympatric with the eastern sand darter.

In West Virginia, both species are sympatric and syntopic within the lower 36 river $\mathrm{km}$ (rkm) of the Elk River, while the eastern sand darter occurs up to $135 \mathrm{rkm}$ from the mouth (Cincotta \& Welsh 2010; personal observations). The western sand darter was recently discovered in the Elk River, which extended the species range to the Eastern Highlands region of North America (Cincotta \& Welsh 2010). The restricted range of the western sand darter compared to that of the eastern sand darter is of conservation concern, since the Elk River is the only known location in West Virginia where the western sand darter persists and represents the southeastern extent for both species (Cincotta \& Welsh 2010)—underscoring the need to examine factors that contribute to dissimilarities between the western and eastern sand darter distributions in the lower Elk River.

Areas of quality habitat are a fundamental component of a fish's ability to grow, survive, and reproduce (e.g., Fisher et al. 2012). Aquatic ecosystems are often subdivided into various classes depending on scale and the species of interest (e.g., ecosystems, streams and rivers, macrohabitats, mesohabitats, and microhabitats). Darters are benthic fish that reside in rivers and lakes (Kuehne \& Barbour 1983). Many species like the western and eastern sand coexist, but are segregated by differences in microhabitat use (Fisher \& Pearson 1987). Substrate composition, depth, and flow velocity are recognized as primary factors influencing the microhabitat use of darters (Chipps \& Perry 1994; Welsh \& Perry 1998; Welsh et al. 2013). However, because of the 
sand darter's burying behavior, individual microhabitat use can be difficult to identify, so sand darter habitat use was evaluated at a sandbar scale.

Furthermore, fish habitat within a river is influenced by water quality, energy source, substrate, channel morphology, flow regimes, and thermal regimes, which are all determined by the various landscape scale factors in the watershed like surficial geology, soil type, bedrock type and depth, watershed topography, land cover, and climate (Wiley et al. 1997; Wang et al. 2003). Understanding the impact of landscape-level variables in structuring fish habitat and thus, a species distribution, is essential for fishes of conservation concern. Frequently, the conservation of rare freshwater stream fish is limited by the deficiency of spatial distribution data and information regarding the association between environmental variables and distribution patterns (Olden et al. 2002; Gibbson et al. 2004). Therefore, predictive species distribution models (SDMs) can aid in filling these knowledge gaps by linking environmental variables to areas that are suitable for a species survival (Guisan \& Zimmermann 2000), as the conservation of rare steam fishes is largely dependent upon understanding a species habitat use in order to identify areas for protection, inventory, and restoration (e.g., Angermeier et al. 2002; Royle et al. 2007).

Burying in sand substrate is an integral component of the western and eastern sand darters' life history. Therefore, determining sandbar preference and landscape-level variables that influence habitat availability are critical for the conservation and management of both species. The purpose of this study was to (1) examine mesohabitat use (i.e., sandbar) for both species of sand darters, (2) model the probability of suitable habitat for the western and eastern sand darter in the Elk River, and (3) explore how environmental variables vary in importance for each species. 


\section{Methods}

Study area

The Elk River is a tributary of the Kanawha River, a part of the Ohio River drainage, and the greater Mississippi River watershed. The Elk River follows a western course, stretching 290 rkm through central West Virginia from northwestern Pocahontas County to the capital city of Charleston, where the Elk River confluences with the Kanawha River. Throughout its course, the Elk River has an elevation change of approximately $900 \mathrm{~m}$ and roughly drains $4,000 \mathrm{~km}^{2}$ of the Appalachian Plateau (Stauffer et al. 1995). The study area for this project is the lower $190 \mathrm{rkm}$ located below the Sutton Dam, which impounds a $6 \mathrm{~km}^{2}$ reservoir. Further downstream, away from the tailwaters of the dam, the river has a low gradient with long deep pools separated by short shoals (Welsh et al. 2013).

\section{Fish collections}

Collections of western and eastern sand darters occurred at 63 sites in the lower $190 \mathrm{rkm}$ of the Elk River between June and October 2015 and 2016 (Fig. 3.1). This section of the river was selected because prior surveys of the upper Elk River did not yield either species of sand darter. The lower 190 rkm below the Sutton Dam was divided into 7 sections, with 3 reaches that were $2 \mathrm{rkm}$ in length per reach, with the target of sampling 3 to 5 sites (i.e., sandbars) per reach. This sampling design was an attempt to evenly distribute the sampling locations throughout the study area; however, this was challenging due to issues of river access across private property. All presence locations were taken using a Garmin handheld global positioning system (GPS) unit. A straight $1.5 \times 3 \mathrm{~m}$ seine with $3 \mathrm{~mm}$ mesh was used at each site to comprehensively sample a sandbar. This included upstream and downstream parallel seine hauls and perpendicular 
hauls pulled into shore (O’Brien \& Facey 2008; Driver \& Adams 2013). Sampling events were intermittent because sampling was restricted to periods of low flow ( $<400 \mathrm{cfs})$, decent water clarity in order to identify sandbars, and wadeable areas of the river $(<1.5 \mathrm{~m})$. Sampled sandbars were generally free of large woody debris and contained at least $90 \%$ sand. The number of seine hauls per site was dependent upon the shape and area of a sandbar. All western and eastern sand darters captured were placed in a holding bucket between hauls, identified to species, counted, and released post seining.

\section{Mesohabitat sampling}

At each of the 63 sites, habitat data were recorded at two spatial scales including the stream site and the individual sandbar. At a given site, focal current velocity $(\mathrm{m} / \mathrm{s}$; bottom velocity), average current velocity $(\mathrm{m} / \mathrm{s} ; 60 \%$ of the depth), and depth $(\mathrm{m})$ were measured at five evenly spaced points across the river channel. Substrate composition was evaluated by conducting four parallel transects perpendicular to the river flow at $1 \mathrm{~m}$ intervals noting the substrate type at each point (silt $<0.06 \mathrm{~mm}$, sand $0.0-2 \mathrm{~mm}$, small gravel $2-16 \mathrm{~mm}$, large gravel 16-64 mm, cobble 64-250 mm, and boulder >250) (Wentworth 1920; Kondolf \& Li 1992; Kaufmann et al., 1999). River width (m) was recorded at each of the four substrate transects using a handheld range finder. At the sandbar, bottom current velocity, average current velocity, and depth were measured at three evenly spaced points along the sandbar. A $200 \mathrm{ml}$ sand sample was collected from the upper $6 \mathrm{~cm}$ at the center of a seine haul where sand darters were detected (Facey \& O'Brien 2004). However, we were not able to gather sand samples from all locations so the sample size is lower for the percent contribution to sand grain sizes (Table 3.2). The sand samples were later dried, sifted using a Gilson $20.3 \mathrm{~cm}(8 \mathrm{in})$ sieve Shaker $(115 \mathrm{~V} / 60 \mathrm{~Hz})$ with 
U.S. Standard sieve screens, and weighed $(0.1 \mathrm{~g})$ to estimate the percent contribution of each sand grain size category (silt $>0.10 \mathrm{~mm}$, fine sand $0.125-0.25 \mathrm{~mm}$, medium sand $0.25-0.5 \mathrm{~mm}$, coarse sand 0.5-1.0 mm, very coarse sand 1.0-2.0 mm, and granule gravel 2.0-4.0 mm; Wentworth 1920; Facey \& O’Brien 2004).

\section{Mesohabitat analysis}

Principal components analysis (PCA) was utilized to examine sandbar habitat variables between sand darter species (Welsh \& Perry 1998; Compton et al. 2013; Gribbs et al. 2014). PCA is a heuristic procedure of unconstrained ordination and is able to elicit trends from multivariate data in reduced space (e.g., Bocard et al. 2011; Gribbs et al. 2014). This approach is based on eigenvectors, which account for the greatest variation explained in the data, eigenvalues greater than one were retained for the analysis (Kawk \& Peterson 2007). Sandbar average current velocity and bottom current velocity were collinear $(r=0.92)$, therefore sandbar average current velocity was removed from further analysis. Data transformation included logit transformation of substrate proportions, square root transformation of depth, bottom current velocity, and natural $\log$ transformation of sandbar area. The PCA incorporated eight habitat variables: sandbar depth, sandbar bottom current velocity, sandbar area, \%fine sand, \%medium sand, \%coarse sand, $\%$ very coarse sand, and \%granule gravel. Habitat variables with factor loadings $\geq 0.40$ were used to elucidate the PCA plot (Fig. 3.2; Kawk \& Peterson 2007). The PCA was conducted using R version 3.2.3 statistical software (R Core Team 2015). The mean, standard error, and range was calculated for all of the habitat variables for each species (Tables $3.1 \& 3.2$ ), and used to examine relationships between habitat variables, species occurrence, and aid in the interpretation of the PCA results. 


\section{Landscape scale analysis}

Fishes that are rare or threatened often have restricted distributions, are habitat specialists and have a limited number of known occurrence locations, which restricts the use of species distribution models to solely modeling presence locations (Hernandez et al. 2006). This is the case for the western and eastern sand darter, because of their burying behavior, individuals could be present at a site and not detected, and as a result only presence locations can be modeled. Maximum entropy modeling (maxent) is one of the few species distribution models designed specifically for presence-only data (Phillips et al. 2006), and this method is effective with small sample sizes as low as 5, 10, and 25 (Hernandez et al. 2006; Elith et al. 2011). Maxent is a machine learning and data driven approach that links georeferenced presence locations with site level or landscape features to generate a probability of occurrence (Philips et al. 2006), which is similarly used as a proxy for the relative suitability of habitat in a given region or a species given niche (Warren \& Seifert 2011). This method is being regularly employed to examine the probably of occurrence of rare stream fishes that are of conservation concern or have limited geographic information (Endries 2011; Labay et al. 2011; Williams et al. 2012; Liang et al. 2013; Albanese et al. 2014).

The software uses the presence locations as training points for the model and environmental layers to estimate a species probability of occurrence or habitat suitability (Phillips et al. 2006). The models were built using maxent version 3.3.3k (Schapire 2016) with program defaults. To test the models for accuracy a subset of the training data (25\%) was randomly selected and withheld. Model performance was assessed using receiver operating characteristic (ROC) curves, a high ROC value $(\geq 0.80)$ for the test data indicates good model fit 
or that there is a high likelihood that the model properly predicts areas of occurrences (high sensitivity) and minimizes the chance of a false positive (high specificity) (Phillips et al. 2011). The logistic output was selected to generate the probability of suitable habitat for each stream reach. The importance of individual environmental variables was examined by assessing the percent contribution to the gain in model fit, response curves, and a jackknife procedure executed in maxent. The jackknife procedure calculates how the gain in the model fit fluctuates as individual environmental variables are included or withheld (Phillips et al. 2011). Maxent is sensitive to selection biases from sampling locations. An attempt was made to account for this by sampling a wide range of sandbars throughout the lower river; however, we were unable to sample the lowest reaches of the Elk River below Mink Shoals. Likewise, maxent has a tendency to overfit models with species that have a patchy distribution or small range, which may have influenced our model results.

\section{Environmental layers}

The explanatory environmental variables were derived using ArcGIS version 10.4. All of the environmental variable layers were extracted to include 14 digit Hydrologic Unit Code (HUC) catchments that intersected the main channel of the Elk River. The catchments were used as proxies for individual river segments (Fig. 3.3; Liang et al. 2013). The catchment scale as a proxy for stream reach was appropriate for our data because we were able to elucidate broad patterns across the landscape that a smaller scale may have overlooked. Environmental variables included contributing drainage area $\left(\mathrm{km}^{2}\right)$, river gradient $(\mathrm{m})$, sinuosity (ratio of deviation from a path), island area $\left(\mathrm{m}^{2}\right)$, geologic classes, and land cover classes (Table 3.4). Contributing drainage area and gradient were derived using Digital Elevation Models (DEMs) at a 10 x $10 \mathrm{~m}$ 
cell size. For the contributing drainage area and gradient layers the streams in the watershed were 'burned' to the DEM, which ensures proper overland flow and true instream elevation values (Callow et al. 2007). The maximum value for each catchment was calculated for contributing drainage area using the zonal statistics as table tool within spatial analyst. Sinuosity was calculated by measuring the center line of the Elk River compared to the straight line distance for each river segment in a catchment. The island layer was extracted from a 1:4,800 streams SAMB layer from the WV GIS technical center. The area of islands within each catchment was calculated using the zonal statistics as table tool to determine the sum of island area in a catchment. The percent of geologic units and land cover types per catchment were calculated using the tabulate area tool. The catchment data (tabulate area and zonal statistics as table) was joined with the catchment layer, each attribute of interest was then converted to a raster layer with a $30 \times 30 \mathrm{~m}$ cell size, and converted to an ASCII file, which is the required file type for maxent. The outputs from maxent in ASCII format were later imported back into ArcGIS, converted back to raster grids, and plotted for better visual interpretation (Fig. 3.3).

\section{Results}

Fish survey

Western and eastern sand darters were detected in dissimilar proportions throughout the lower Elk River. Of the 63 sites sampled western sand darters were detected at 2 sites, eastern sand darters were detected at 41 sites, both species overlapped at 6 sites, and neither species was detected at 14 sites (Fig. 3.1). Western sand darters were detected predominantly near the town of Clendenin (36 rkm), and at 2 sites further downstream near Blue Creek (19 rkm). In contrast to eastern sand darters, which were detected from Mink Shoals $(7.8 \mathrm{rkm})$ upstream to Frametown 
(135 rkm) (Fig. 3.1). Due to high flows and deeper channel depth sampling did not occur below Mink Shoals. Previous surveys of the lower Elk River detected western sand darters near Big Chimney and Mink Shoals (Fig. 3.1; Cincotta \& Welsh 2010). Because of the sand darters elusive nature, it is possible that western and eastern sand darters were present at a site and not detected. The greatest abundance of western sand darters were detected at two locations near Clendenin $(n=12$ and $n=8)$. The greatest abundance of eastern sand darters were located near Porter Creek ( $n=99)$, Strange Creek $(n=77)$, and Big Chimney $(n=50)$. The sample size of occurrence data of the western sand darter was low (sites $=8$ ) compared to the eastern sand darter (sites $=47)$.

\section{Mesohabitat}

The type of depositional area (i.e., sandbars) varied depending on the species. Western and eastern sand darters were detected in longitudinal sandbars downstream from a riffle with rippled sand and at sandbars located on the downstream end of an island. Sites where eastern sand darters were exclusively detected included meander point bars, longitudinal bars downstream from a meander, shallow embayments, main channel pool sections, and sandbars where a tributary joins the main channel. Western sand darters were associated with sandbars that had higher average current velocity (mean $=0.20 \mathrm{~m} / \mathrm{s}, \mathrm{SE}=0.03 \mathrm{~m} / \mathrm{s}$ ), compared to those that were solely occupied by eastern sand darters (mean $=0.10 \mathrm{~m} / \mathrm{s}, \mathrm{SE}=0.02 \mathrm{~m} / \mathrm{s}$ ). The sandbars where western sand darter $\left(\right.$ mean $\left.=263.44 \mathrm{~m}^{2}\right)$ were detected were on average larger than the sandbars where only eastern sand darters $\left(\right.$ mean $=130.81 \mathrm{~m}^{2}$ ) were detected (Table 3.1). On average, western sand darters were detected at sites with higher proportions of sand and smaller substrates compared to the eastern sand darter only sites (Table 3.1). Sandbars where 
species were syntopic had higher proportions of coarse sand, while sandbars where solely eastern sand darters were detected contained higher proportions of fine and medium sand (Table 3.2).

The principal components analysis plot likewise demonstrated differences among habitat use between species (Fig. 3.2). The first three principal components (PCs) contained eigenvalues greater than one, which accounted for $67 \%$ of the variation in the data (Table 3.2). A total of $54 \%$ of the variation was explained by the first (39\%) and by the second (15\%) principal components used for the PC plot (Table 3.3; Fig. 3.2). Principal component 1 factor loadings $\geq$ 0.40 include $\%$ fine sand $(0.84), \%$ medium sand $(0.64), \%$ coarse sand $(-0.92), \%$ very coarse sand (-0.82), and \%granule gravel (-0.68) (Table 3.3). Values that loaded highly on PC2 include sand bar depth (0.52), and sandbar area (-0.76). Sand darter species habitat use differed along both PC axes. Based on the factor loadings, the PC1 axis represents a depositional gradient from larger substrate to smaller substrate from the left to right, while the PC2 axis represents sandbar area and sandbar depth. Based on the factor loadings, western sand darters most often occurred in areas with a higher percentages of coarse grained sand, faster bottom current velocity and larger sandbars, while eastern sand darters were more of a generalist, occurring in a wide variety of sandbars throughout the lower Elk River.

\section{Landscape scale}

The maxent species distribution models displayed a medium probability of suitable habitat within the currently occupied reaches with higher probabilities downstream and lower probabilities further upstream (Fig. 3.3). The highly suitable areas for the western and eastern sand darter reflect known historical locations (Welsh \& Perry 1998; Cincotta \& Welsh 2010), but the western sand darter sample size was near the minimum level for using maxent (Hernandez et 
al. 2006). The highest probabilities of suitable habitat in the study area were up to 0.77 for the western sand darter and up to 0.76 for the eastern sand darter. The probability of suitable habitat for the western sand darter increased downstream of $40 \mathrm{rkm}$ and drastically deceased upstream of $46 \mathrm{rkm}$ (Fig. 3.3). The probability of suitable habitat for the eastern sand darter began to increase downstream of $80 \mathrm{rkm}$, and decreased upstream of $123 \mathrm{rkm}$ (Fig. 3.3). The areas where the probability of suitable habitat for both species was highest ranged from 7 rkm to 36 rkm (Fig. 3.3).

Performance within the models and on the test data was high for both species. The receiver operating characteristic (ROC) curve for the test data for the western sand darter model was 0.899 , while the ROC curve for the eastern sand darter was 0.875 . The western sand darter model had 6 training points and 2 test points. The eastern sand darter model used 34 presence locations for the training data and 11 for testing. The high AUC value for the western sand darter model is related to the small sample size and the species narrow range (Phillips 2011). The ROC curves for both models are well above the random prediction line indicating that the models are better than random.

Contributing drainage area had the largest percent contribution to model gain for each species (Table 3.5). Percent contribution to model gain for the western sand darter included contributing drainage area $(79.7 \%)$, sinuosity $(19.7 \%)$, island area $(0.3 \%)$, and percent developed $(0.3 \%)$. Compared to the eastern sand darter model, which included contributing drainage area $(84 \%)$, island area $(7.1 \%)$, gradient $(4 \%)$, percent sandstone $(2.5 \%)$, and sinuosity $(1.8 \%)$. Contributing drainage area, island area, and sinuosity comprised at least $90 \%$ of the contribution to model gain for both species. Jackknife tests produced similar results for each species, with contributing drainage area providing the largest gain when included separately in the model. The 
equal test sensitivity and specificity results indicate significant presence thresholds for the western sand darter $(p=0.02)$ and the eastern sand darter $(p<0.01)$. Logistic values greater than 0.526 for the western sand darter, and greater than 0.449 for the eastern sand darter indicate significant presence. A wider range of suitable habitat is available for the eastern sand darter, compared to the western sand darter. Overall, 20\% of the river below Sutton Dam contained habitat with $\mathrm{a} \geq 50 \%$ probability of suitable habitat for the western sand darter, while the eastern sand darter model predicted $32 \%$ of the lower river has suitable habitat.

Dissimilarities between the variables were further examined by assessing response curves for the variables with the highest contribution to model gain. The response curves for contributing drainage area showed a low probability $(<50 \%)$ of suitable habitat below $3,000 \mathrm{~km}^{2}$ for the western sand darter and $2,400 \mathrm{~km}^{2}$ for the eastern sand darter (Fig. 3.4). Sinuosity impacted model gain inversely for each species, the probability of presence drastically declined with values $>1.0$ for the western sand darter, whereas the eastern sand darter probability of presence increased (Fig. 3.4). The probability of presence decreased as the gradient increased for both species. There was an inverse relationship with area of islands in each catchment. Western sand darter probability of presence increased with island area, while eastern sand darter probability of presence decreased with island area. Overall, western sand darters were restricted to the lower reaches, while the probability of suitable habitat is higher further upstream for the eastern sand darter. The main landscape scale factors that appear to impact range differences for each species are contributing drainage area, sinuosity, island area, and gradient.

\section{Discussion}


This research represents the first inquiry into western and eastern sand darter habitat use at multiple scales in a region where they are sympatric as well as syntopic. Sand darters are commonly considered rare and elusive, which has resulted in a scarcity of information regarding habitat and ranges (Kuehne \& Barbour 1983). The assessment of multiple scales for habitat use is essential to understanding the persistence of threatened species (e.g., Labbe \& Fausch 2000). The mesohabitat assessment provided more detailed insight on sandbar characteristics, while the landscape-level approach allowed us to investigate habitat use, despite limited western sand darter locations and the restriction of presence only data. The sand darter focused survey of the lower Elk River found that western sand darters continue to be restricted to the lower $36 \mathrm{rkm}$, whereas the eastern sand darters distribution extends another $100 \mathrm{rkm}$ upstream. Western sand darters were detected at larger more contiguous sandbars with a moderate flow and at sites with high proportions of coarse grained sand, while eastern sand darters were not limited to faster velocities and were detected in a wide variety of sandbars. Geology and land cover types minimally impacted the habitat suitability models, while physical characteristics of the river contributed to the greatest proportions of model gains.

Eastern sand darters were detected at times in areas that initially seemed suboptimal on account of low flow and fine sediment, whereas western sand darters were typically detected in large sandbars with moderate flow. Results from a substrate selection laboratory study of the western and eastern sand darter reported significant differences amongst sand grain size preferences between species (see Chapter 2). The authors reported that western sand darters selected for a narrower range of coarser grains $(0.25-1.0 \mathrm{~mm})$, compared to the more generalist eastern sand darter $(0.125-1.0 \mathrm{~mm})$. These finding were mirrored with data from the field, with the western sand darter occurring in sandbars with higher proportions of coarse grained sand, 
compared to the sandbars that were solely occupied by eastern sand darters. Additionally, our field results were similar to past eastern sand darter habitat use studies with the species preferring sandbars with high proportions of fine to medium sand (Daniels 1993; Facey \& O'Brien 2004; Tesslar et al. 2012; Dextrase et al. 2014). Thus, the sorting of sand gain sizes may vary depending on the type and location of a sandbar, which could influence differences in habitat suitability between the two species.

The landscape-level western and eastern sand darter models reflected known range differences between the two sand darter species in the lower Elk River, and further supports the idea that individual sandbars vary throughout the rivers course. Physical features throughout a river system change in a continuum, which structures aquatic habitat (e.g., Vannote et al. 1980; Jackson et al. 2001). Thus, physical factors like contributing drainage area and gradient are known to heavily influence stream fish distribution models (Endries 2011; Liang et al. 2013; Albanese et al. 2014). Habitat suitability for each species increased with higher contributing drainage area values and decreased with higher river gradient values, while the relationship to sinuosity was inversely related.

Given that western sand darters are restricted to the lower Elk River, it is important to consider how contributing drainage area may influence the creation of sandy depositional areas. As contributing drainage area increases downstream, the river's discharge and cumulative sediment supply also increase, while the river's erosional energy dissipates allowing for greater deposition in the lower reaches of the river (e.g., Charlton 2007). Sediment is deposited during a number of circumstances, which include a reduction in flow discharge, a decrease in river gradient, an increase in river width, an increase in boundary resistance, flow separation (large difference in velocity between fast moving flow and slowly recirculating flow), and obstruction 
to flow (e.g., Charlton 2007). These deposits create various types of sandbars (smaller depositional features) within a river's channel, which are commonly located on the inside of meander bends (point bars), downstream of islands, along the edges of channels (shallow embayments \& longitudinal bars), main channel pool sections, and where tributaries join the main channel. Eastern sand darters were detected in all the sandbars mentioned above, whereas western sand darters were solely collected from sandbars with rippled sand downstream of a riffle or from sandbars located on the downstream end of an island.

The relationship between sinuosity, sand darter presence, and habitat suitability is uncertain. Sinuosity is a measure of the ratio between channel length and straight-line valley length. In general, a river's sinuosity is known to change in proportion to discharge; as discharge increases a river will become more sinuous further downstream (Leopold \& Wolman 1957). Exceptions to this baseline assumption occur when there is valley confinement (i.e., resistive valley walls limit lateral channel migration) or when the river gradient is low, causing a reduction in stream power, which reduces the river's ability to erode channel banks (e.g., Charlton 2007). This may be the case in the lower $36 \mathrm{rkm}$ of the Elk River, where this stretch of river is less sinuous compared upstream reaches. Increased sinuosity does create depositional areas like meander point bars (Charlton 2007); however, western sand darters were not detected in this type of sandbar in contrast to eastern sand darters. Additionally, the increased sinuosity upstream may increase habitat fragmentation or widen the distance between sandbars.

Furthermore, the presence of the Sutton Dam in the Elk River likely alters seasonal flow and temperature regimes, the frequency and magnitude of channel discharge, and sediment scour and depositional patterns (Baxter 1977; Power et al. 1996). Discharge patterns are known to influence cohort success via the maintenance of sandy depositional habitats and increased 
nutrient inputs from flood-pulse events (Gutreuter et al. 1999; Lin \& Caramaschi 2005). High mean annual discharge and sand-dominated habitat provided the greatest first year growth for eastern sand darters in Ontario (Drake et al. 2008). The strong positive relationship of age-0 growth and high mean annual discharge was related to the flood-pulse concept, where frequent high discharge events decrease the amount of siltation, and increase nutrient inputs to nearshore areas (Junk et al. 1989). The Elk River experiences seasonal flooding; however, the dam alters the duration of those events, reduces the sediment load below the dam, erodes channel banks, and alters variation in seasonal discharge (Poff \& Hart 2002). The effect of sediment reductions downstream may be less pronounced in the lower reaches of the Elk River by additional sediment added to the system from contributing tributaries (Ligon et al. 1995). Highlighting the importance of natural flow regimes, and the need to enhance our understanding of how impoundments effect the geomorphic processes that drive the creation of physical habitats in rivers.

Rivers are highly complex, dynamic systems, making it challenging to pin down variables that impact a species distribution. However, with the combination of a mesohabitat and landscape-level investigation we were able to provide some insight on factors that may be influencing the sand darters range dissimilarities in the Elk River. The sorting of sand gain sizes and the size of a sandbar vary depending on its position in the river, which influence differences in habitat suitability between the western and eastern sand darter. Because these species do burry in the sand, individuals can be difficult to detect. Likewise, sampling for this study was restricted to wadeable areas of the river and did not include deeper pool sections that may contain either species. Thus, further surveys in the Elk River and other rivers that contain both species are needed to improve the applicability of our mesohabitat results and the sand darter models. Biotic 
factors like competition or predation may play a role in structuring the sand darter community; however, for the purpose of this project we were limited to examining habitat use factors influencing range dissimilarities. The western and eastern sand darters are often regarded at indicators of aquatic ecosystem health because the sandy stream beds they inhabit must be free of siltation to allow for oxygen uptake, burying, and egg development (Drake et al. 2008). Conservation and management of rare freshwater fishes must consider multiple scales, from landscape-level processes that structure instream habitat to more fine-scale mesohabitats that regulate local populations. Information gained from studying the western and eastern sand darters distribution and habitat use may be applied to future monitoring efforts, as well as future conservation and management decisions in the Elk River watershed.

\section{Acknowledgements}

The authors appreciate the field and laboratory assistance provided by J. Aldinger, B. Crabill, K. Lambert, B. Tierney. Additional thanks to M. Strager of West Virginia University and D. Cincotta from the West Virginia Division of Natural Resources. This study was performed under the auspices of West Virginia University IACUC protocol 15-0801. Any use of trade, firm, or product names is for descriptive purposes only and does not imply endorsement by the U.S. Government.

\section{Literature Cited}

Albanese B, Litts T, Camp M, Weiler DA. 2014. Using occupancy and species distribution models to assess the conservation status and habitat use of the goldline darter (Percina aurolineata) in Georgia, USA. Ecol Freshw Fish 23(3):347-359 
Angermeier PL, Krueger KL, Dolloff CA. 2002. Discontinuity in stream fish distributions: implications for assessing and predicting species occurrence. Pages 519-527 in J. M. Scott, P. J. Heglund, M. L. Morrison, J. B. Haufler, M. G. Raphael, W. A. Wall and F. B. Samson, editors. Predicting Species Occurrences: Issues of Accuracy and Scale. Island Press, Covelo, California.

Baxter RM. 1977. Environmental effects of dams and impoundments. Annu Rev Ecol Syst, pp 255-283.

Borcard D, Gillet F, and Legendre P. 2011. Numerical Ecology with R, Springer, Springer Science Business Media, LLC, pp 115-151.

Callow JN, Van Niel KP, Boggs GS. 2007. How does modifying a DEM to reflect known hydrology affect subsequent terrain analysis?. J Hydrol. 332(1):30-39.

Charlton R. 2007. Fundamentals of fluvial geomorphology. Routledge. New York, NY.

Chipps SR, Perry WB, Perry SA. 1994. Patterns of microhabitat use among four species of darters in three Appalachian streams. Am Mid Nat. 131:175-180.

Cincotta DA, Welsh SA. 2010. Discovery of Ammocrypta clara (Western Sand Darter) in the Upper Ohio River of West Virginia. Am Mid Nat. 163(2):318-325.

Compton M, Taylor C. 2013. Spatial scale effects on habitat associations of the Ashy Darter, Etheostoma cinereum, an imperiled fish in the southeast United States. Ecol Freshw Fish 22(2):178-191.

Daniels RA. 1993. Habitat of the Eastern Sand Darter, Ammocrypta pellucida. J Freshw Ecol. $8: 287-295$. 
Dextrase AJ, Mandrak NE, Schaefer JA. 2014. Modelling occupancy of an imperiled stream fish at multiple scales while accounting for imperfect detection: implications for conservation. Freshw Biol. 59(9):1799-1815.

Drake DAR, Power M, Koops MA, Doka SE, Mandrak NE. 2008. Environmental factors affecting growth of eastern sand darter (Ammocrypta pellucida). Can J Zool. 86:714-722.

Driver LJ, Adams GL. 2013. Life history and spawning behavior of the Western Sand Darter (Ammocrypta clara) in northeast Arkansas. Am Mid Nat. 170(2):199-212.

Elith J, Graham CH, Anderson RP, Dudı'k M, Ferrier S, Guisan A, Hijmans RJ, Huettmann F, Leathwick JR, Lehmann A, Li J, Lohmann LG, Loiselle BA, Manion G, Moritz C, Nakamura M, Nakazawa Y, McC Overton J, Townsend Peterson A, Phillips SJ, Richardson K, Scachetti-Pereira R, Schapire RE, Soberón J, Williams S, Wisz MS, Zimmermann NE. 2006. Novel methods improve prediction of species' distributions from occurrence data. Ecography 29(2):129-151.

Elith J, Phillips SJ, Hastie T, Dudík MY, Chee E, Yates CJ. 2011. A statistical explanation of MaxEnt for ecologists. Divers Distrib. 17(1):43-57.

Endries M. 2011. Aquatic Species Mapping in North Carolina Using Maxent. U.S. Fish and Wildlife Service, Ecological Services Field Office, Ashville, NC.

Facey DE, O'Brien SM. 2004. Influence of substrate composition on distribution of eastern sand darters (Ammocrypta pellucida) in the Poultney River. Pages 291 - 297 in T. O. Manley, P. L. Manley, and T. B. Mihuc, editors. Lake Champlain: partnerships and research in the new millennium. Kluwer Academic/Plenum Publishers, New York, NY. 
Fisher WL, Pearson WD. 1987. Patterns of resource utilization among four species of darters in three central Kentucky streams. Community and evolutionary ecology of North American stream fishes. University of Oklahoma Press, Norman, 69-76.

Fisher WL, Bozek AB, Vokoun JC, Jacobson RB. 2012. Freshwater aquatic habitat measurements. Pages 101-150 in A. V. Zale, D. L. Parish, and T. M. Sutton, editors. Fisheries techniques, $3^{\text {rd }}$ edition. American Fisheries Society, Bethesda, MD.

Gibbs WK, Miller JE, Cook SB, Kulp MA. 2014. Habitat use and dispersal of a reintroduced Etheostoma sitikuense (Citico Darter) population. Southeastern Nat. 13(1):40-55.

Gibson LA, Wilson BA, Cahill DM, Hill J. 2004. Spatial prediction of rufous bristlebird habitat in a coastal heathland: a GIS-based approach. J Appl Ecol. 41(2):213-223.

Grandmaison D, Mayasich J, Etnier D. 2004. Eastern sand darter status assessment. US Fish and Wildlife Service, Region, 3. NRRI Technical Report No. NRRI/TR-2003/40.

Gutreuter S, Bartels AD, Irons K, Sandheinrich MB. 1999. Evaluation of the flood-pulse concept based on statistical models of growth of selected fishes of the Upper Mississippi River system. Can J Fish Aquat Sci. 56:2282-2291.

Guisan A, Zimmermann NE. 2000. Predictive habitat distribution models in ecology. Ecol Model. 135(2):147-186.

Hernandez PA, Graham CH, Master LL, Albert DL. 2006. The effect of sample size and species characteristics on performance of different species distribution modeling methods. Ecography 29(5):773-785.

Jackson DA, Peres-Neto PR, Olden JD. 2001. What controls who is where in freshwater fish communities the roles of biotic, abiotic, and spatial factors. Can J Fish Aquat Sci. 58(1):157-170. 
Junk WJ, Bayley PB, Sparks RE. 1989. The flood pulse concept in river-floodplain systems. Can Spec Pub Fish Aquatic Sci. 106(1):110-127.

Kaufmann PR, Levine P, Peck DV, Robison EG, Seeliger C. 1999. Quantifying physical habitat in wadeable streams. USEPA National Health and Environmental Effects Research Laboratory, Western Ecology Division.

Kondolf GM, Li S. 1992. The pebble count technique for quantifying surface bed material size in instream flow studies. Rivers 3(2):80-87.

Kuehne RA, Barbour RW. 1983. The American Darters. The University Press of Kansas, pp 177.

Kwak TJ, Peterson JT. 2007. Community indices, parameters, and comparisons. Pages 677-763 in C.S. Guy and M. L. Brown, editors. Analysis and Interpretation of Freshwater Fisheries Data. American Fisheries Society, Bethesda, MD.

Labbe TR, Fausch KD. 2000. Dynamics of intermittent stream habitat regulate persistence of a threatened fish at multiple scales. Ecol Appl. 10(6):1774-1791.

Labay B, Cohen AE, Sissel B, Hendrickson DA, Martin FD, Sarkar S. 2011. Assessing historical fish community composition using surveys, historical collection data, and species distribution models. PLoS One 6(9):e25145.

Leopold LB, Wolman MG. 1957. River channel patterns: Braided, Meandering, and Straight. U.S. Geological Survey, No. 282-B.

Liang L, Fei S, Ripy JB, Blandford BL, Grossardt T. 2013. Stream habitat modelling for conserving a threatened headwater fish in the Upper Cumberland River, Kentucky. River Res Appl. 29(10):1207-1214.

Ligon FK, Dietrich W.E, Trush WJ. 1995. Downstream ecological effects of dams. BioSci. 45(3):183-192. 
Lin DSC, Caramaschi TP. 2005. Responses of the fish community to the flood pulse and siltation in a floodplain lake of the Trombetas River, Brazil. Hydrobiologia 545:75-91.

Near TJ, Porterfield JC, Page LM. 2000. Evolution of cytochrome b and the molecular systematics of Ammocrypta (Percidae: Etheostomatinae). Copeia 2000(3):701-711.

O'Brien SM, Facey DE. 2008. Habitat use by the Eastern Sand Darter, Ammocrypta pellucida, in two Lake Champlain tributaries. Can Field Nat. 122(3):239-246.

Olden JD, Jackson DA, Peres-Neto PR. 2002. Predictive models of fish species distributions: a note on proper validation and chance predictions. Trans Am Fish Soc. 131(2): 329-336.

Page LM, Burr BM. 2011. Peterson field guide to freshwater fishes of North America and North of Mexico. Second edition, Houghton Mifflin Harcourt, Boston, MA. pp. 534-535.

Phillips SJ, Dudík M, Schapire RE. 2004. A maximum entropy approach to species distribution modeling. In Proceedings of the twenty-first international conference on Machine learning, p. 83.

Phillips SJ, Anderson RP, Schapire RE. 2006. Maximum entropy modeling of species geographic distributions. Ecol Model. 190(3):231-259.

Phillips SJ. 2011. A brief tutorial on MaxEnt. Available online at http://www.cs.princeton.edu/ schapire/maxent/. Accessed 27 April 2016.

Poff NL, Hart DD. 2002. How dams vary and why it matters for the emerging science of dam removal. BioSci. 52(8):659-668.

Power ME, Dietrich WE, Finlay JC. 1996. Dams and downstream aquatic biodiversity: potential food web consequences of hydrologic and geomorphic change. Environ Manag. 20(6):887-895. 
Royle JA, Kery M, Goutier R, Schmid H. 2007. Hierarchical spatial models of abundance and occurrence from imperfect survey data. Ecol Monogr. 77:465-481.

Schapire RE. 2016. Maxent software for species habitat modeling. Available at: http://www.cs.princeton.edu/ schapire/maxent/. Accessed 24 April 2016.

Stauffer Jr J, Boltz JM, White LR. 1995. Fishes of West Virginia. Academy of Natural Sciences 146:1-389.

Tessler NR, Gottgens JF, Kibbey MR. 2012. The first observations of the Eastern Sand Darter, Ammocrypta pellucida (Agassiz), in the Ohio portion of the Maumee River mainstem in sixty-five years. Am Mid Nat. 167(1):198-204.

Vannote RL, Minshall GW, Cummins KW, Sedell JR, Cushing CE. 1980. The river continuum concept. Can J Fish Aquat Sci. 37(1):130-137.

Wang L, Lyons J, Rasmussen P, Seelbach P, Simon T, Wiley M, Kanehl P, Baker E, Niemela S, Stewart PM. 2003. Watershed, reach, and riparian influences on stream fish assemblages in the Northern Lakes and Forest Ecoregion, USA. Can J Fish Aquat Sci. 60(5):491-505.

Warren Jr ML, Burr BM, Walsh SJ, Bart Jr HL, Cashner RC, Etnier DA, Ross ST. 2000.

Diversity, distribution, and conservation status of the native freshwater fishes of the southern United States. Fisheries 25(10):7-31.

Warren DL, Seifert SN. 2011. Ecological niche modeling in Maxent: the importance of model complexity and the performance of model selection criteria. Ecol Appl. 21(2):335-342.

Welsh SA, Perry SA. 1998. Habitat partitioning in a community of darters in the Elk River, West Virginia. Environ Biol Fish. 51:411-419.

Welsh SA, Smith DM, Taylor ND. 2013. Microhabitat use of the diamond darter. Ecol Freshw Fish 22:587-595. 
Wentworth CK. 1922. A scale of grade and class terms for clastic sediments. J Geol. 30:377-392.

Wiley MJ, Kohler SJ, Seelbach PW. 1997. Reconciling landscape and local views of aquatic communities: lessons from Michigan trout streams. Freshwater Biol. 37:133-148.

Williams JD. 1975. Systematics of the percid fishes of the subgenus Ammocrypta, genus Ammocrypta, with descriptions of two new species. Bulletin of the Alabama Museum of Natural History 1:1-56.

Williams L, Smith C, Wolf C. 2012. Using ecological niche modeling to predict the probability of occurrence of rare fish and mussel species in East Texas. Endangered Species Program, Texas Parks and Wildlife Service, Austin, TX. 
Table 3.1. Means, standard errors (SE) and ranges of western and eastern sand darter habitat use variables for 63 sites in the Elk River,

WV. Western sand darters were detected at 8 sites, eastern sand darters were detected at 47 sites, and neither species were detected at

14 sites. A total of 6 sites contained both species. Bottom current velocity (FCV) and average current velocity (ACV) for the site and

sandbar.

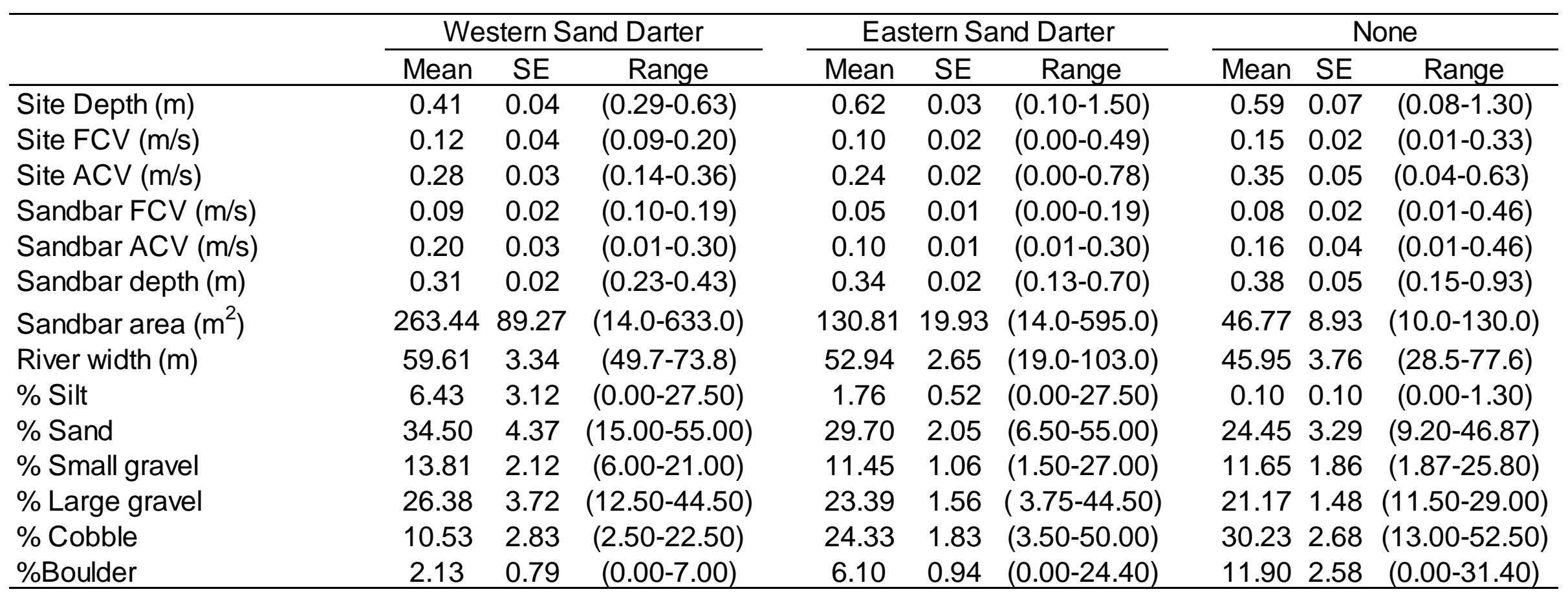


Table 3.2. Mean values for percent composition of sandbar grain size, standard error (SE) and ranges. Sand samples for the western sand darter were collected at 6 sites, and 36 sites for the eastern sand darter.

\begin{tabular}{lcccccccc}
\hline & \multicolumn{3}{c}{ Western sand darter } & & \multicolumn{3}{c}{ Eastern sand darter } \\
\cline { 2 - 3 } \cline { 7 - 9 } & Mean & SE & Range & & & Mean & SE & Range \\
\hline \% Silt & 0.39 & 0.15 & $(0.00-0.94)$ & & 1.27 & 0.20 & $(0.00-4.67)$ \\
\% Fine sand & 0.94 & 0.21 & $(0.32-1.42)$ & & 6.36 & 1.28 & $(0.00-45.96)$ \\
\% Medium sand & 40.81 & 3.91 & $(28.37-51.46)$ & & 67.65 & 5.90 & $(31.69-93.55)$ \\
\% Coarse sand & 54.48 & 3.58 & $(46.28-66.67)$ & & 22.19 & 3.12 & $(0.77-62.91)$ \\
\% Very coarse sand & 2.88 & 0.69 & $(1.42-6.08)$ & & 2.15 & 0.42 & $(0.00-12.26)$ \\
\% Granule gravel & 0.51 & 0.22 & $(0.00-1.42)$ & & 0.40 & 0.08 & $(0.00-1.75)$ \\
\hline
\end{tabular}


Table 3.3. The principal components (PC) with eigenvalues $\geq 1.0$, the percent variance explained by each PC, and a list of variables examined by principal components analysis (PCA) with their corresponding factor loading. Bolded factor loading $(\geq 0.40)$ were used to interpret the axes of PC1 and PC2.

\begin{tabular}{lccc}
\hline & PC1 & PC2 & PC3 \\
\hline Eigenvalues & 3.49 & 1.32 & 1.2 \\
\% Variance explained & 39 & 15 & 13
\end{tabular}

Variables

Sand bar depth $(\mathrm{m})$

Area of sand bar $\left(\mathrm{m}^{2}\right)$

$0.28 \quad 0.52 \quad-0.47$

Bottom current velocity $(\mathrm{m} / \mathrm{s})$

$\begin{array}{lll}-0.11 & -0.76 & 0.17\end{array}$

$\%$ Fine sand

$\begin{array}{lll}-0.40 & -0.34 & 0.24\end{array}$

$\%$ Medium sand

$\begin{array}{lll}0.64 & 0.27 & 0.47\end{array}$

$\%$ Coarse sand

$\mathbf{0 . 8 4}-0.22 \quad-0.11$

$\%$ Very coarse sand

$\begin{array}{lll}-0.92 & 0.07 & -0.10\end{array}$

$\%$ Granule gravel

$\begin{array}{lll}-0.82 & 0.32 & 0.14\end{array}$

\begin{tabular}{lll}
-0.68 & 0.19 & 0.32 \\
\hline
\end{tabular}


Table 3.4. Environmental layers used to generate the species distribution models.

\begin{tabular}{|c|c|c|c|c|}
\hline Variable & Scale & Source & Projection & Description \\
\hline \multicolumn{5}{|l|}{ Stream Derived } \\
\hline Drainage Area & $1: 24,000$ & USGS National Elevation Dataset & UTM NAD83 zone 17 & $\begin{array}{l}\text { Cumulative maximum drainage area in } \mathrm{km}^{2} \text {. Derived from } 10 \mathrm{~m} \text { Digital } \\
\text { Elevation Models (DEMs). }\end{array}$ \\
\hline Gradient & $1: 24,000$ & USGS National Elevation Dataset & UTM NAD83 zone 17 & Slope of a stream segment in m (rise/ run). Derived from 10 m DEMs. \\
\hline Sinuosity & $1: 24,000$ & $\begin{array}{l}\text { Natural Resource Analysis Center, West } \\
\text { Virginia University, High-resolution } \\
\text { National Hydrography Dataset }\end{array}$ & UTM NAD83 zone 17 & A measure of deviation from a path. \\
\hline Islands & $1: 4,800$ & $\begin{array}{l}\text { WV GIS Technical Center Statewide } \\
\text { Addressing and Mapping Project } \\
\text { (streams SAMB) }\end{array}$ & UTM NAD83 zone 17 & Area of islands in each catchment in $\mathrm{m}^{2}$. \\
\hline \multicolumn{5}{|c|}{ Land Cover Classes } \\
\hline$\%$ Developed & $1: 40,000$ & $\begin{array}{l}\text { USGS Multi-resolution Land } \\
\text { Characteristics Consortium, National } \\
\text { Land Cover Database } 2011\end{array}$ & UTM NAD 83 zone 17 & $\begin{array}{l}\text { Consists of a range of developed intensities that include constructed } \\
\text { materials, impervious surfaces, and densely populated area. Class types } 21 \text { - } \\
24 \text { and } 31 .\end{array}$ \\
\hline$\%$ Forested & $1: 40,000$ & $\begin{array}{l}\text { USGS Multi-resolution Land } \\
\text { Characteristics Consortium, National } \\
\text { Land Cover Database } 2011\end{array}$ & UTM NAD 83 zone 17 & Deciduous, evergreen, and mixed forests. Class types 41-43. \\
\hline \multicolumn{5}{|c|}{ Geologic Classes } \\
\hline$\%$ Shale & $1: 250,000$ & WV Geological \& Economic Survey & UTM NAD83 zone 17 & $\begin{array}{l}\text { Clastic sedimentary rocks composed of mud, clay, silt and other minerals like } \\
\text { quartz and calcite. }\end{array}$ \\
\hline$\%$ Sandstone & $1: 250,000$ & WV Geological \& Economic Survey & UTM NAD83 zone 17 & $\begin{array}{l}\text { Clastic sedimentary rocks composed of mainly sand-sized minerals that are } \\
\text { primarily quartz and/or feldspar. }\end{array}$ \\
\hline
\end{tabular}


Table 3.5. The estimates of the relative percent contribution of the environmental variables to the maxent models created for the western and eastern sand darters.

\begin{tabular}{lcc}
\hline & $\begin{array}{c}\text { Western } \\
\text { Sand Darter }\end{array}$ & $\begin{array}{c}\text { Eastern } \\
\text { Sand Darter }\end{array}$ \\
\cline { 2 - 3 } Variables & \multicolumn{2}{c}{$\%$ Contibution } \\
\hline Drainage area $\left(\mathrm{km}^{2}\right)$ & 79.7 & 84 \\
Gradient $(\mathrm{m})$ & 0 & 4 \\
Island area $\left(\mathrm{m}^{2}\right)$ & 0.3 & 7.1 \\
Sinuosity & 19.7 & 1.8 \\
$\%$ Sandstone & 0 & 2.5 \\
$\%$ Shale & 0 & 0.3 \\
\% Developed & 0.3 & 0.3 \\
\% Forested & 0 & 0 \\
\hline
\end{tabular}


- Western Sand Darter

\& Western \& Eastern Sand Darter

- Eastern Sand Darter

None Detected

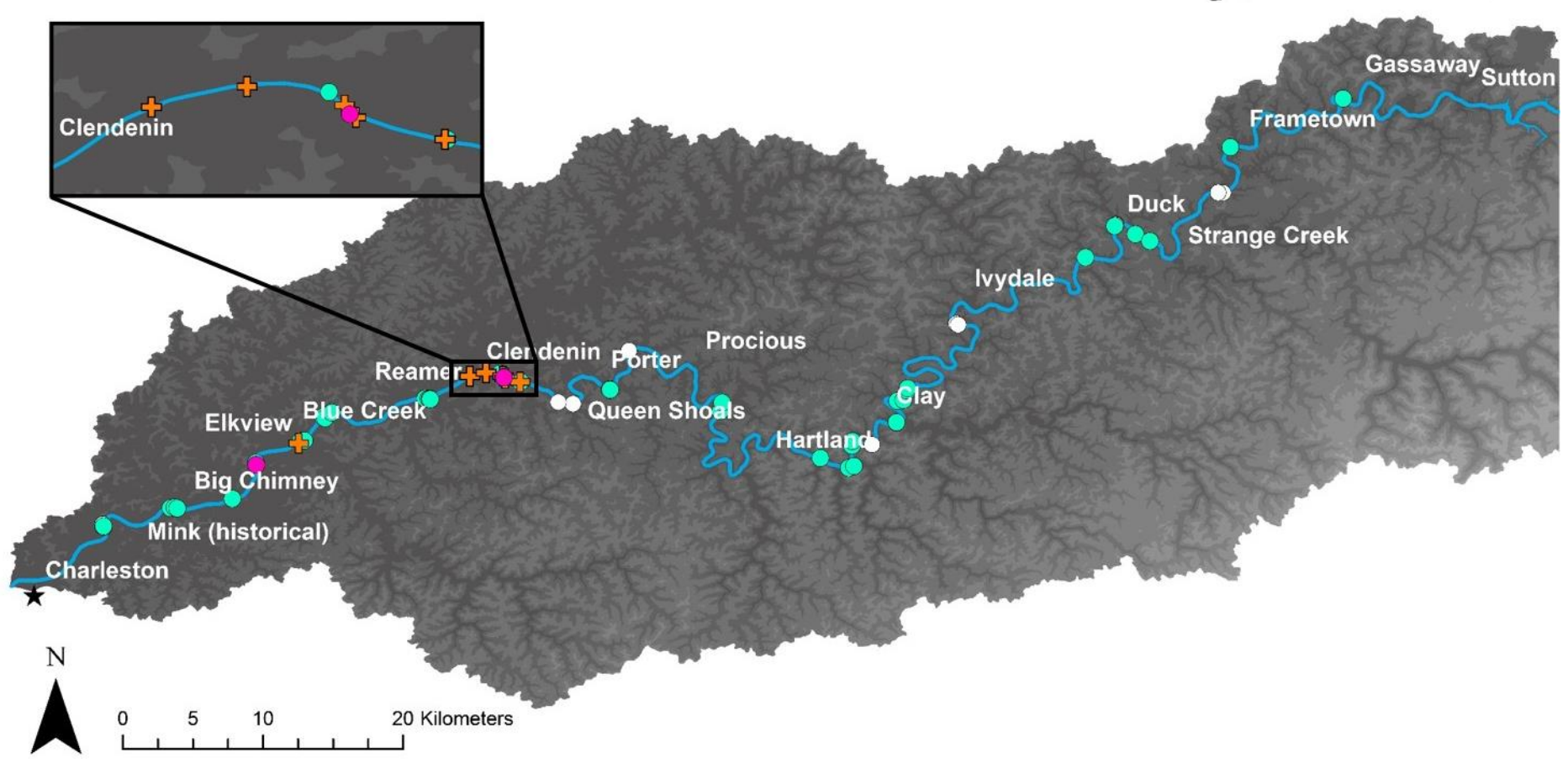

Figure 3.1. Western and eastern sand darter sampling locations in the lower $190 \mathrm{rkm}$ of the Elk River watershed shaded by elevation. 


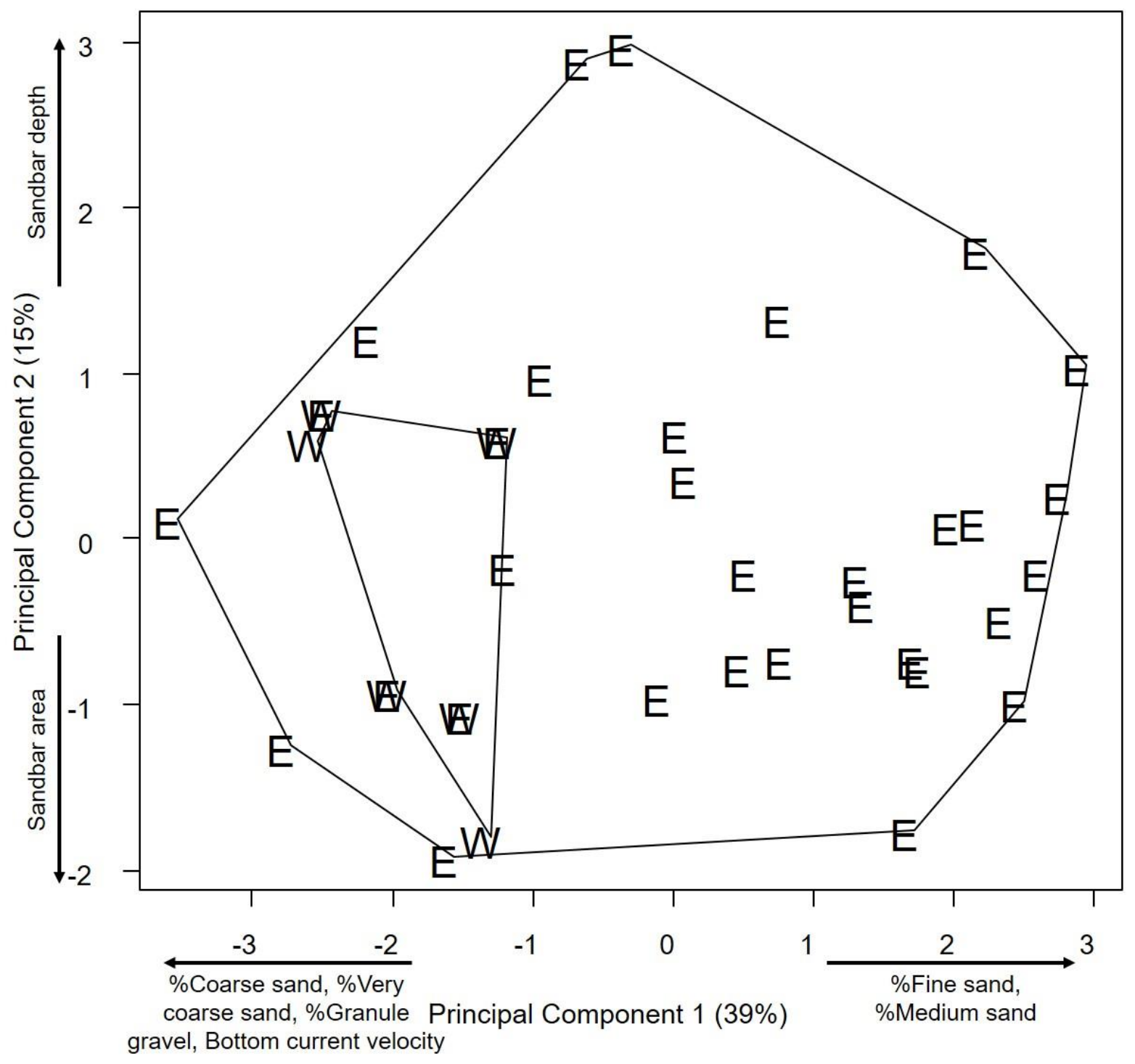

Figure 3.2. Principal components analysis plot of sand darter habitat use with overlaid polygons showing the variance between species. Each point represents a sampling site where either western sand darters (W) or eastern sand darters (E) were detected. Axis loadings $\geq 0.40$ are listed. 


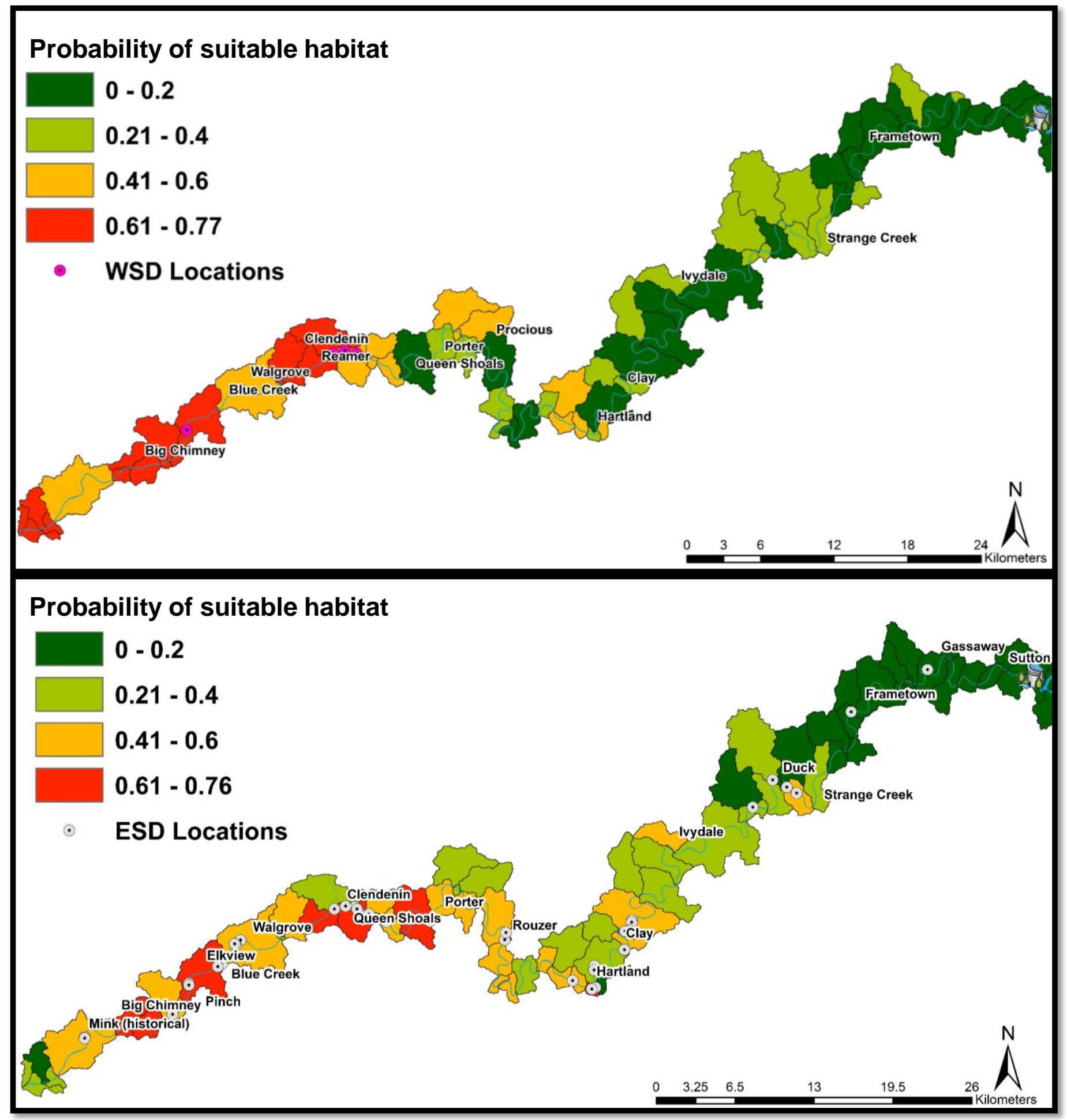

Figure 3.3. Probability of suitable habitat for the western sand darter (WSD) and eastern sand darter (ESD) by 14 digit HUC catchments in the lower Elk River. 

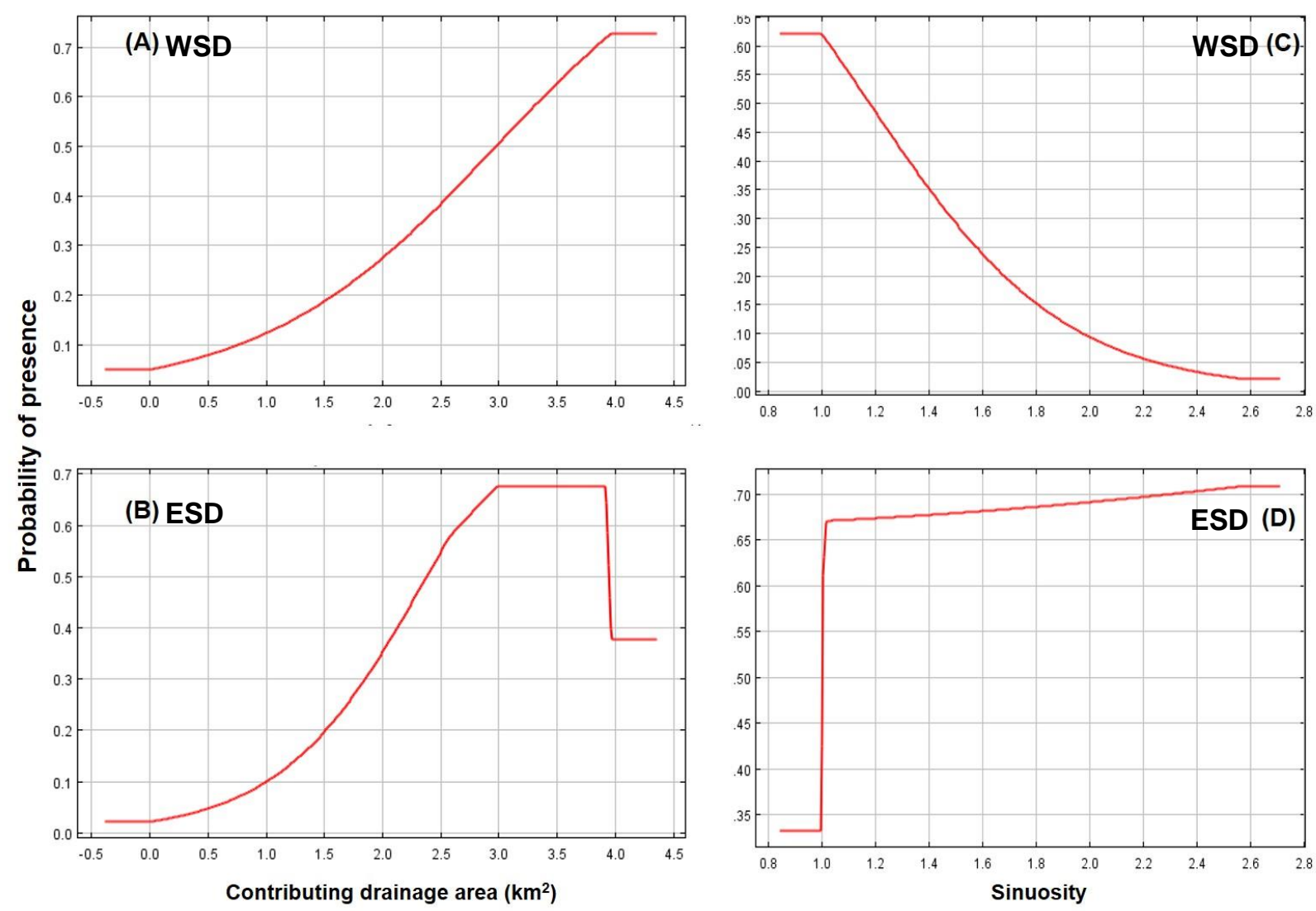

Figure 3.4. The response curves demonstrate how contributing drainage area and sinuosity affect the maxent predictions for the western sand darter (WSD) and the eastern sand darter (ESD). The curves show how the logistic prediction changes as the environmental variable are varied, keeping all other environmental variables at their average value. Contributing drainage area is in thousands (i.e., $1.0=1,000$ ). 